Linköping Studies in Science and Technology

Dissertation No. 1572

\title{
Synthesis of Carbon-based and Metal-Oxide Thin Films using High Power Impulse Magnetron Sputtering
}

\section{Asim Aijaz}

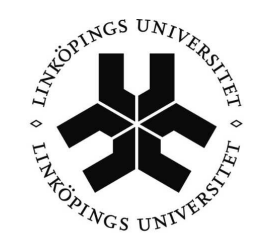

Linköping University INSTITUTE OF TECHNOLOGY

Plasma \& Coatings Physics Division

Department of Physics, Chemistry and Biology (IFM)

Linköping University

SE-581 83 Linköping, Sweden 
(C) Asim Aijaz 2014

ISBN: 978-91-7519-408-0 ISSN 0345-7524

Printed by LiU-tryck

Linköping, Sweden, 2014 
To my mother 



\section{Abstract}

The work presented in this thesis deals with synthesis of carbon-based as well as metaloxide thin films using highly ionized plasmas. The principal deposition method employed was high power impulse magnetron sputtering (HiPIMS). The investigations on plasma chemistry, plasma energetics, plasma-film interactions and its correlation to film growth and resulting film properties were made. The thesis is divided into two parts: (i) HiPIMSbased deposition of carbon-based thin films and (ii) HiPIMS-based deposition of metaloxide thin films.

In the first part of the thesis, HiPIMS based strategies are presented that were developed to address the fundamental issues of low degree of carbon ionization and low deposition rates of carbon film growth in magnetron sputtering. In the first study, a new strategy was introduced for increasing the degree of ionization of sputtered carbon via increasing the electron temperature in the discharge by using a higher ionization potential buffer gas $(\mathrm{Ne})$ in place of commonly used Ar. A direct consequence of enhanced electron temperatures was observed in the form of measured large fluxes of ionized carbon at the substrate position. Consequently, high mass densities of the resulting amorphous carbon (a-C) thin films reaching $2.8 \mathrm{~g} / \mathrm{cm}^{3}$ were obtained.

In another study, feasibility of HiPIMS-based high density discharges for high-rate synthesis of dense and hard a-C thin films was explored. A strategy was compiled and implemented that entailed coupling a hydrocarbon precursor gas $\left(\mathrm{C}_{2} \mathrm{H}_{2}\right)$ with high density discharges generated by the superposition of HiPIMS and direct current magnetron sputtering (DCMS). Appropriate control of discharge density (by tuning HiPIMS/DCMS power ratio), gas phase composition and energy of the ionized depositing species lead to a route capable of providing ten-fold increase in the deposition rate of a-C film growth compared to that obtained using HiPIMS Ar discharge in the first study. The increased deposition rate was achieved without significant incorporation of $\mathrm{H}(<10 \%)$ and with relatively high hardness $(>25 \mathrm{GPa})$ and mass density $\left(\sim 2.32 \mathrm{~g} / \mathrm{cm}^{3}\right)$. The knowledge gained in this work was utilized in a subsequent work where the feasibility of adding high 
ionization potential buffer gas $(\mathrm{Ne})$ to increase the electron temperature in an $\mathrm{Ar} / \mathrm{C}_{2} \mathrm{H}_{2}$ HiPIMS discharge was explored. It was found that the increased electron temperature lead to enhanced dissociation of hydrocarbon precursor and an increased $\mathrm{H}$ incorporation into the growing film. The resulting a-C thin films exhibited high hardness ( $25 \mathrm{GPa})$, mass densities in the order of $2.2 \mathrm{~g} / \mathrm{cm}^{3}$ and $\mathrm{H}$ content as low as about $11 \%$. The striking feature of the resulting films was low stress levels where the films exhibited compressive stresses in the order of $100 \mathrm{MPa}$.

In the second part of the thesis, investigations on reactive HiPIMS discharge characteristics were made for technologically relevant metal-oxide systems. In the first study, the discharge characteristics of Ti-O and Al-O were investigated by studying the discharge current characteristics and measuring the ion flux composition. Both, Ti-O and Al-O discharges were dominated by large fluxes of ionized metallic as well as sputtering and reactive gases species. The generation of large ionized fluxes influenced the discharge characteristics consequently surpassing the changes in the secondary electron emission yields which, in the case of DCMS discharges entail contrasting behavior of the discharge voltage for the two material systems. The study also suggested that the source of oxygen ions in the case of reactive HiPIMS is both, the target surface (via sputtering) as well as gas phase.

In a subsequent study, the knowledge gained from the studies on metal-oxide HiPIMS discharges was utilized for investigating the behavior of reactive HiPIMS discharges related to ternary compound thin film growth. In this work Al-Si-O system, which is a promising candidate for anti-reflective and solar thermal applications, was employed to carry out the investigations under varied target compositions ( $\mathrm{Al}, \mathrm{Al}_{0.5} \mathrm{Si}_{0.5}$, and $\mathrm{Al}_{0.1} \mathrm{Si}_{0.9}$ ). It was found that the discharge current behavior of metal and oxide modes of Al-Si-O HiPIMS discharges were similar to those of Al-O and were independent of the target composition. The influence of energy and composition of the ionized depositing fluxes on the film growth was also investigated. It was shown that stoichiometric Al-Si-O thin films exhibiting a refractive index below 1.6 (which is desired for anti-reflective applications) can be grown. Furthermore, the refractive index and chemical composition 
of the resulting films were found to be unchanged with respect to the energy of the depositing species.

The effect of ionized deposition fluxes that are generated in metal-oxide HiPIMS discharges was also investigated for the phase composition and optical properties of $\mathrm{TiO}_{2}$ thin films. It was found that energetic and ionized sputtered flux in reactive HiPIMS can be used to tailor the phase formation of the $\mathrm{TiO}_{2}$ films with high peak powers facilitating the rutile phase while the anatase phase can be obtained using low peak powers. It was also demonstrated that using HiPIMS, these phases can be obtained at room temperature without external substrate heating or post-deposition annealing. The results on plasma and film properties were also compared with DCMS. 


\section{Populärvetenskaplig sammanfattning}

I denna avhandling presenteras resultatet efter studier av tunnfilmssyntes av kol och av metalloxider nyttjande en avancerad plasmametod. Denna metod, som heter högeffektpulsad-magnetronsputtering (på engelska high power impulse magnetron sputtering förkortat HiPIMS), nyttjar det faktum att den tillförda momentaneffekten till plasma kan ökas mångdubbelt genom att pulsa effekten. På så sätt hålles medeleffekten tillräckligt låg så att uppvärmningen inte processutrustningen blir för stor. Genom den höga effekten i plasmat joniseras både sputtergas och beläggningsmaterial mycket effektivt. I arbetet har relationer mellan plasmaegenskaper och de tillverkade skikten undersökts.

I den första delen av avhandlingen, som berör kolfilmer, har en metod utvecklats som ger betydligt högre jonisationsgrad av kolet än vad som hittills har presenterats. Kol är särskilt svårt att jonisera i ett sputterplasma pga liten storlek och hög jonisationsenergi. Den ökande joniseringen har åstadkommits genom att höja plasmaelektronernas energi. Den ökade elektronenergin är ett resultat $\mathrm{i}$ att en alternativ sputtergas har använts. Normalt nyttjas argon men här har i stället neon använts. Detta resulterade $i$ att höga beläggningsflöden av enkeljoniserat kol kunde uppmätas. Detta är viktigt vid framställning kolfilmer med hög densitet och hög andel diamantbindningar och resulterande filmer fick en amorf struktur och erhöll en densitet $2.8 \mathrm{~g} / \mathrm{cm}^{2}$.

För att öka beläggningshastigheten med kol testades även ett alternativ där inte bara kol som sputtras används utan dessutom den kolinnehållande gasen etyn (även kallad acetylen, $\mathrm{C}_{2} \mathrm{H}_{2}$ ) tillsattes. Detta resulterade $\mathrm{i}$ att beläggningshastigheten kunde ökas tiofalt, men den erhållna filmdensiteten blev något lägre $\left(2.32 \mathrm{~g} / \mathrm{cm}^{2}\right)$. Anmärkningsvärt är att vätehalten i filmerna understiger $10 \%$ trots riklig tillgång till väte i processen genom tillförseln från $\mathrm{C}_{2} \mathrm{H}_{2}$. Genom att utnyttja datorberäkningar (Monte-Carlo) och data från litteraturen föreslås den höga beläggningshastigheten och den låga vätehalten bero på: (i) sönderdelning av det tillförda kolvätet genom växelverkan med energetiska 
elektroner i plasmat vilket ger fritt kol som kan bidra till filmtillväxten (ii) filmens struktur och väteinnehåll påverkas av bombardemang av energetiska joner från plasmat.

Dessa resultat uppmuntrade till ytterligare studier. Denna gång genom att kombinera resultaten presenterade ovan genom att tillsätta både neon och etyn till sputtergasen. Detta resulterade även i detta fall till en ökande elektronenergi, men även till något ökat väteinnehåll i filmerna. I detta fall fick de amorfa kolfilmerna en hårdhet så hög som 25 $\mathrm{GPa}$, en densitet på $2.2 \mathrm{~g} / \mathrm{cm}^{3}$ och en vätehalt på $11 \%$. Utmärkande för dessa filmer vara att de erhöll anmärkningsvärt låga inbyggda spänning, uppmätt till i storleksordningen $100 \mathrm{MPa}$

I andra delen av avhandlingen berör studiet av användandet av reaktiv tunnfilmsframställning av olika tekniskt relevanta metalloxider med HiPIMS. Första arbetet inkluderade studiet av Ti-O och Al-O, där plasmaegenskaperna studerades. Det inkluderar urladdningsförloppets beteende och jonflödets sammansättning från plasmat. Vanligtvis styrs plasmat urladdningsförlopp mest av kemin på sputterkällans yta. Undersökningen här visar att vid användandet av HiPIMS är det mer komplicerat än så och stora flöden av syrejoner dominera beteendet.

En uppföljande studie av ett ytterligare mer komplicerat material involverar Al-Si-O av olika sammansättningar. Detta material är en lovande kandidat som en komponent i antireflexbehandling av, t.ex. solfångare. Det visade sig att urladdningsföloppet liknade det som uppmättes för $\mathrm{Al}-\mathrm{O}$ oberoende av $\mathrm{Al}$-Si-sammansättningen som användes $\left(\mathrm{Al}_{0.5} \mathrm{Si}_{0.5}\right.$, till $\left.\mathrm{Al}_{0.1} \mathrm{Si}_{0.9}\right)$. I reaktiva sputterförhållanden där $\mathrm{Si}-\mathrm{O}$ dominerar förväntas att elektronproduktionen vid sputterkällan skall dominera urladdningsprocessen, men även i detta fall visade det sig att syrejonerna är den dominerande laddningsbäraren. De filmer som växtes med detta material uppvisar ett lågt brytningsindex, mindre än 1,6 vilket också är önskvärt för tillämpningar i fråga.

Ett annat material som studerats är $\mathrm{TiO}_{2}$, ett material som används som en optisk ytbeläggning för att erhålla olika optiska fenomen men också för att materialet är fotokatalytiskt vilket kan hålla en yta ren om den utsätts för solljus. Beroende på vilka egenskaper man vill optimera så vill man kunna använda olika faser av $\mathrm{TiO}_{2}$. När man 
växer material med HiPIMS så kan man nyttja de skapade jonerna för att bombardera skiktet under tillväxt. Med hjälp av detta jonbombardemang kan önskad fas erhållas. 


\section{Preface}

This Dissertation Thesis comprises of the research work that I carried out during my $\mathrm{PhD}$ studies in the Plasma and Coatings Physics Division of the Department of Physics, Chemistry and Biology (IFM) at Linköping University from April 2009 to March 2014. The research was financially supported by the Swedish Research Council (VR).

The results from the research work are presented in the appended papers. Preceding the appended papers, the thesis contains an introduction to the field, the adopted methodology and techniques used for carrying out the research work. The contents of the introductory part are largely based on my Licentiate Thesis No. 1537, HiPIMS-based Novel Deposition Processes for Thin Films, published in June 2012.

Asim Aijaz

Linköping, February 2014 


\section{Appended Papers}

Part I: HiPIMS-based Deposition of Carbon-based Thin Films

1. A strategy for increased carbon ionization in magnetron sputtering discharges

Asim Aijaz, Kostas Sarakinos, Daniel Lundin, Nils Brenning, Ulf Helmersson Diamond and Related Materials, 23 (2012) 1.

2. Principles for designing sputtering-based strategies for high-rate synthesis of dense and hard amorphous carbon thin films

Asim Aijaz, Kostas Sarakinos, Mohsin Raza Khan, Jens Jensen, Ulf Helmersson

Accepted for publication in Diamond and Related Materials, February 2014.

3. Synthesis of amorphous carbon thin films using acetylene-based high power impulse magnetron sputtering discharges

Asim Aijaz, Sascha Louring, Jens Jensen, Kostas Sarakinos, Ulf Helmersson

In final preparation.

\section{Part II: HiPIMS-based Deposition of Metal-Oxide Thin Films}

4. Understanding the discharge current behavior in reactive high power impulse magnetron sputtering of oxides

Montri Aiempanakit, Asim Aijaz, Daniel Lundin, Ulf Helmersson, Tomas Kubart

Journal of Applied Physics, 113 (2013) 133302.

5. Exploring the potential of high power impulse magnetron sputtering for the synthesis of Al-Si-O based scratch-resistant, antireflective coatings Asim Aijaz, Montri Aiempanakit, Stefan Bruns, Ulf Helmersson, Michael Vergöhl and Kostas Sarakinos

In preparation.

6. Effect of peak power in reactive high power impulse magnetron sputtering of titanium dioxide

Montri Aiempanakit, Ulf Helmersson, Asim Aijaz, Petter Larsson, Roger Magnusson, Jens Jensen and Tomáš Kubart

Surface \& Coating Technology, 205 (2011) 4828. 


\section{Contribution to the appended papers}

In Paper I, I was involved in planning of the study, performed all experiments, took part in the analysis of the results and wrote a major part of the paper.

In Paper II, I was responsible for planning of the study, performed a large part of film characterization, performed simulations, performed analysis of the results and wrote the paper.

In Paper III, I lead the planning of the study, performed film synthesis and major part of film characterization, performed plasma characterization, analyzed the results and wrote the paper.

In Paper IV, I was involved in planning of the study, took part in all experiments and analysis of the results and co-wrote the paper.

In Paper V, I was involved in planning of the study, performed film synthesis and plasma characterization, took part in the analysis of the results and wrote the paper.

In Paper VI, I was involved in planning of the study, took part in film synthesis and characterization, performed plasma characterization and took part in writing the paper. 


\section{Other Publications}

1. Patent: Sputtering process for sputtering a target of carbon

Ulf Helmersson, Nils Brenning, Asim Aijaz

SE 536285 (C2), WO 2012/138279 (A1).

2. Dual-magnetron open field sputtering system for sideways deposition of thin films

Asim Aijaz, Daniel Lundin, Petter Larsson, Ulf Helmersson

Surface and Coatings Technology, 204 (2010), 2165-2169.

3. A novel high-power pulse PECVD method

Henrik Pedersen, Petter Larsson, Asim Aijaz, Jens Jensen and Daniel Lundin

Surface and Coating Technology, 206 (2012), 4562-4566.

4. Deposition of yttria-stabilized zirconia thin films by high power impulse magnetron sputtering and pulsed magnetron sputtering

Steffen Sønderby, Asim Aijaz, Ulf Helmersson, Kostas Sarakinos, Per Eklund Accepted for publication in Surface and Coatings Technology (December 2013). 


\section{Conference contributions}

1. Highly ionized carbon plasmas for the growth of diamond-like carbon thin films using magnetron sputtering, International Conference on Metallurgical Coatings and Thin Films (ICMCTF), April 2013, San Diago, U.S.A.

Contributing author to an oral presentation

2. Synthesis of wear resistant, anti-reflective Al-Si-O thin films using reactive high power impulse magnetron sputtering: Investigations on the plasma composition and plasma energetics, Reactive Sputter Deposition (RSD), December 2012, Ghent, Belgium.

Oral presentation

3. Highly ionized carbon fluxes for the growth of diamond-like carbon films using magnetron sputtering, International Conference on Diamond and Carbon Materials (ICDCM), September 2012, Granada, Spain.

Oral presentation

4. Highly ionized carbon fluxes for the growth of diamond-like carbon films using magnetron sputtering, European Material Research Society (E-MRS), May 2012, Strasbourg, France.

Oral presentation

5. Towards achieving a high degree of carbon ionization in magnetron sputtering discharges, Reactive Sputter Deposition (RSD), December 2011, Linköping, Sweden.

Oral presentation

6. Towards achieving a high degree of carbon ionization in magnetron sputtering discharges, American Vacuum Society (AVS), October 2011, Nashville, U.S.A.

Oral presentation

7. Towards synthesizing high density and $\mathrm{sp}^{3}$ rich carbon films using high power impulse magnetron sputtering, International Conference on HiPIMS, June 2011, Braunschweig, Germany.

Oral presentation

8. Dual-magnetron open field sputtering system for sideways deposition of thin films $12^{\mathrm{th}}$ International Conference on Plasma Surface Engineering (PSE), September 2010, Garmisch-Partenkirchen, Germany.

Poster presentation 


\section{Acknowledgements}

Through the course of this journey which extended over six years at Linköping University, there are many people who have contributed substantially towards my success. I would like to take this opportunity to extend my deepest and sincere gratitude towards all of them.

Ulf Helmersson; my main-supervisor, thank you for giving me the opportunity to work in the group, for all kinds of support, guidance, supervision and most important of all, being patient and supportive.

Kostas Sarakinos; my co-supervisor; you have always inspired me with your knowledge, dedication for science and hard work. Beyond that, you have always been there whenever I failed to see things differently i.e. positively. Sir! You are a true Gent.

All co-authors; thank you for putting your time and efforts to make thing work for me.

All other members of the Plasma and Coatings Physics division, for creating an atmosphere of quality research together with fun. A big Thank You goes to Mattias Samuelsson, Daniel Lundin, Daniel Magnfält and Montri Aiempanakit for the good company on- and off-campus.

Friends and colleagues in the Thin Film Physics and Nanostructured Materials Divisions and others in IFM. A special gratitude is due towards Junaid and Naureen. Thank you for your company, whether it was the time that I spent together with you during travelling, Tea-breaks or the long discussions that we had on almost every topic, each and everything will be with me all along my life in the form of good memories.

All my Pakistani friends in Sweden; you all have contributed towards whatever I have achieved. Thank you very much for making my stay in Sweden, a memorable part of my life. An special appreciation goes to Abdus Samad and Imran Mohsin. 
My friends in Pakistan; thank you for staying in touch while being so far. I have never forgotten any of you during over six years of stay away from Pakistan. Your friendship is an integral part of my life!

All my family members; it has been very tough to live without you for so long a time. I have always missed being with you. You mean everything to me!

My wife Yasra and my 9 months old daughter Anabiya; without whom this thesis would have been completed one year ago:) I would like to take this opportunity to apologize for not giving you the time you deserved due to heavy workload. You both are part of me! You have filled my life with joy and in You, I see myself living. I am simply nothing without you.

Finally, the most important person in my life, my Mother; You have brought me where I am today. I have never forgotten, not for a single moment, the hardships that you have seen throughout your life and the hard work that you have put in making a good life for all your children. I cannot describe your contribution in words. I love you a lot! 


\section{Contents}

Abstract

Populärvetenskaplig sammanfättning …………….................................... V

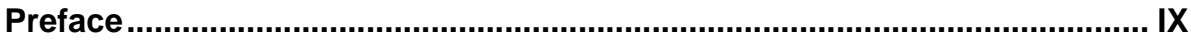

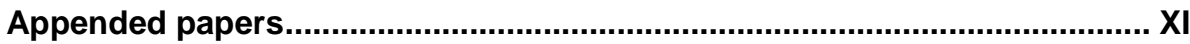

Contribution to the appended papers ........................................................ XII

Other publications ............................................................................................. XIII

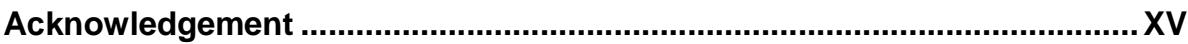

1.Introduction ................................................................................................

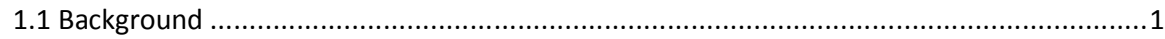

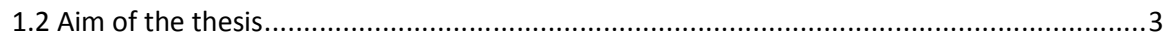

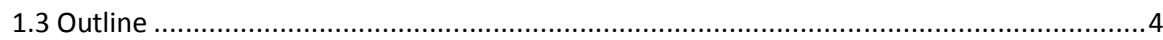

2.Basic Plasma Physics ............................................................................ 5

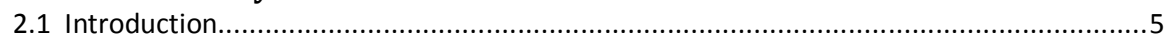

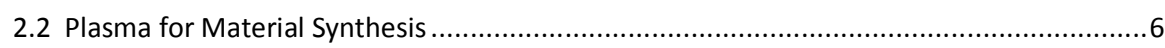

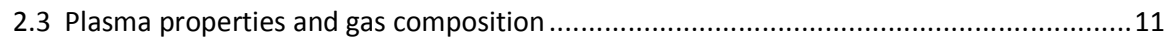

2.3.1 Effect of change of buffer gas................................................................... 11

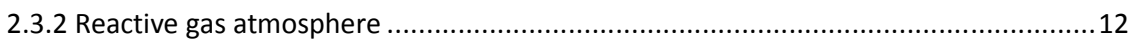

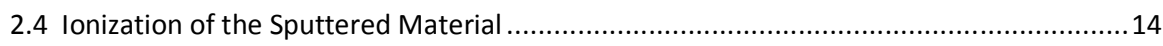

3.Thin Film Deposition Processes .................................................................19

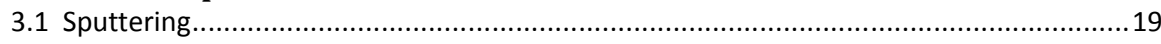

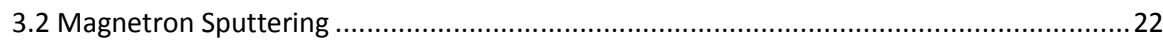

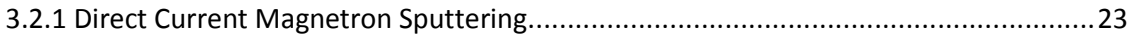

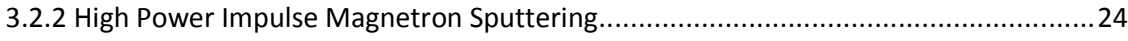




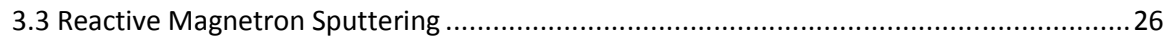

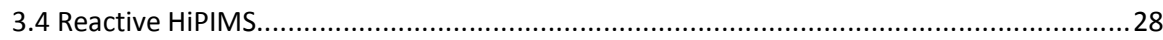

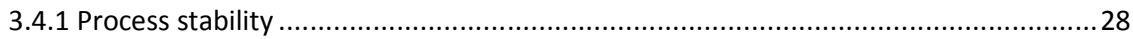

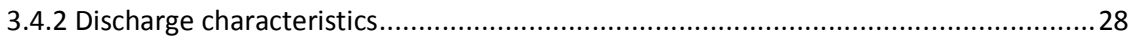

4.Thin Films Growth and Materials Systems................................................ 31

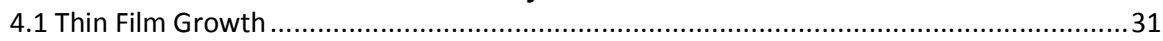

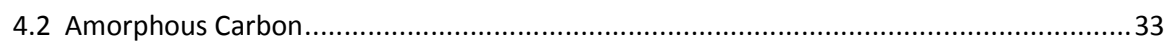

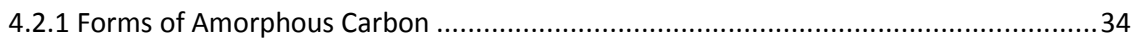

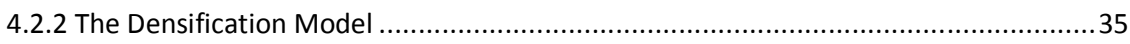

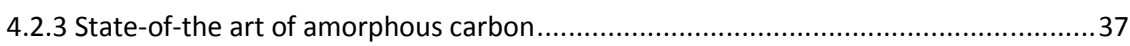

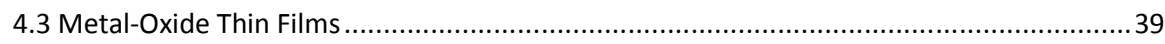

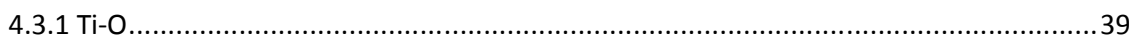

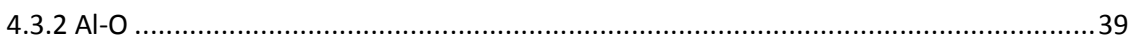

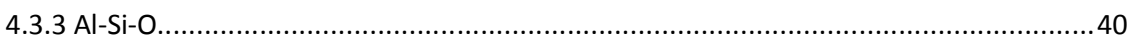

5.Plasma and Thin Film Characterization ..................................................41

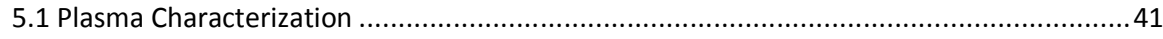

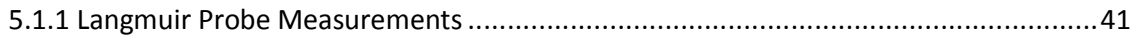

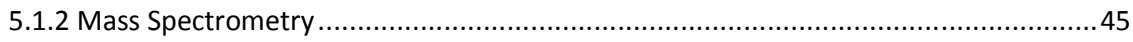

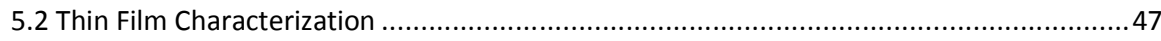

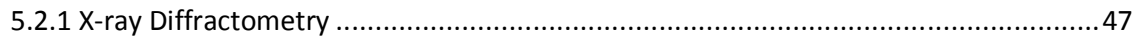

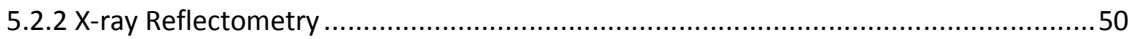

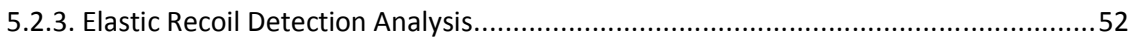

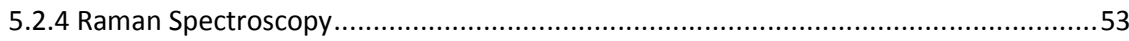

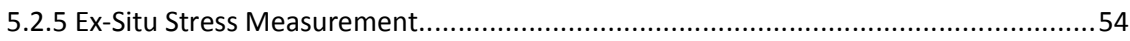

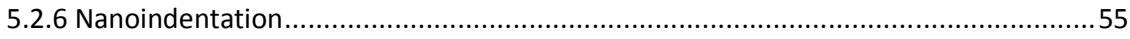

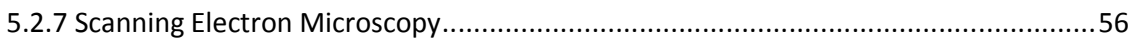

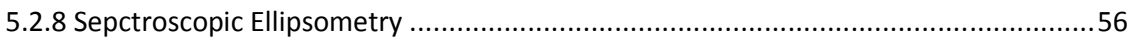

6.Summary and contribution to the field ..................................................57

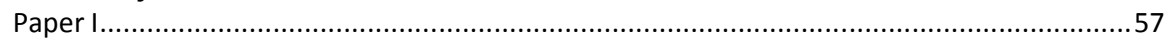

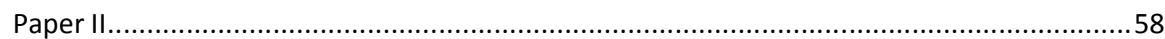




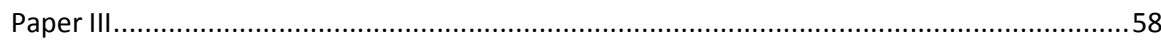

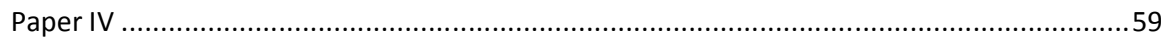

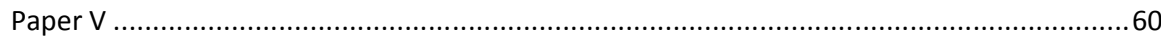

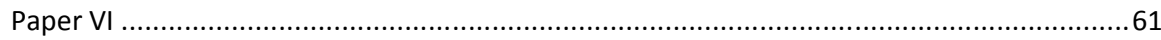

7.Additional results and future outlook ...........................................................63

References.....................................................................................................65

Paper I - VI 


\section{Chapter 1}

\section{Introduction}

\subsection{Background}

Thin films are structures with thickness ranging from several nanometers up to several micrometers that are formed when atomic layers of a material are deposited on a surface of an object to alter properties as well as to add to the functionality of the latter [1]. Thin film deposition on an object not only provides means to alter and enhance the properties of the underlying surface, it also paves the way for the development of new structures exhibiting properties that are unique to the combined film-surface system. This opens up possibilities for designing thin film based structures for new applications. At present thin films are found in applications ranging from house-hold objects to high-tech and advanced machinery and devices. Examples of thin films are protective coatings on eyeglasses, cutleries, cutting tools, functional coatings for medical-implants, thin films used in solar panels, thin films used in electronic devices (such as hard disks, computer chips etc.), to name just a few [2]. The ultimate goal of thin film science and technology is to widen up the range of applications as well as improve on the existing products by synthesizing thin film structures with tailored properties while focusing also on the production efficiency. Thin films that concern this thesis are based on carbon and metaloxides. The applications of these thin films cover areas including, but not limited to, protective coatings, tribology, optics etc.

The structure and properties of thin films, besides the material itself, depend largely on the deposition process characteristics. Various deposition methods are employed for thin film deposition at laboratory as well as at industrial scale. Common among these are based on chemical vapor deposition (CVD) and physical vapor deposition (PVD) [3]. In CVD, thin film deposition is carried out by thermally induced chemical reactions of 
volatile gases (also called precursors) on a substrate (object that is desired to be coated) $[3,4]$. CVD processes facilitate conformal deposition that allow for homogenous thin film deposition on complex-shaped substrates. A variety of materials, from metal to organic compounds, can be deposited using CVD [3]. A drawback that is inherent to the process is its limitation for thin film deposition on temperature sensitive substrates due to high process temperatures involved [2,3]. The issue can be overcome to a certain extent by coupling a plasma in the so-called plasma enhanced CVD (PECVD) where the chemical reactions triggered by the plasma allow for relatively low-temperature synthesis of thin films [2,4]. In PVD, the vapor of the material that is desired to be coated as thin films is created by physical means such as by laser ablation, thermal evaporation, sputtering using a plasma etc. $[1,3]$. The vapor thus created condensate on a substrate to form thin film. Common PVD based approaches include arc evaporation; where the source material is vaporized via a high current arc at the surface $[2,3,5]$, laser ablation; where the depositing material is ejected as a result of an energy transfer from a laser beam photons to the target atoms [6] and magnetron sputtering where ions from a plasma bombard the target surface thereby ejecting the target atoms via momentum transfer [1,7]. Often, a hybrid PVD and CVD arrangement is also employed in order to combine the benefits from the two methods [2].

The methods that have been employed for carbon-based and metal-oxide thin film deposition in this thesis are based on magnetron sputtering. There are several variants of magnetron sputtering, most widely used among these are direct current magnetron sputtering (DCMS) and radio frequency magnetron sputtering (RFMS) [3,7]. A relatively newly developed magnetron sputtering based method is high power impulse magnetron sputtering (HiPIMS) [8-10] which is the principal deposition method employed for carrying out research work presented in this thesis. HiPIMS is essentially a modification of DCMS with a difference lying in the fact that the former delivers a significantly higher instantaneous power $\left(\mathrm{kW} / \mathrm{cm}^{2}\right.$ as compared to $\left.\mathrm{W} / \mathrm{cm}^{2}\right)[8-10]$ to the sputtering target (the term target is typically used for the source in sputtering). The result is a conversion of conventional sputtering source into an ion source where the large fraction of the sputtered material is in the form of ions. This facilitates a control over energy and direction of the depositing flux which allows for tailoring the film structure and properties [11,12]. 
For carbon-based thin films, the structure and properties are mainly dependent on the hybridization state of carbon atoms (i.e. $\mathrm{sp}^{3} / \mathrm{sp}^{2}$ bond ratio) [13] in the films and can be controlled by controlling the energy and flux of the depositing species [13]. DCMS and RFMS have been widely used for a-C film growth $[14,15]$ however, owing to their inability to generate large ionized $\mathrm{C}$ fluxes [8] these methods are not always suitable for synthesizing carbon-based thin films exhibiting a wide range of properties. HiPIMS has demonstrated its potential to overcome this difficulty $[15,16]$ however, previous reports on HiPIMS-based synthesis of a-C suggest that the ionized fraction of $\mathrm{C}$ using HiPIMS is still much lower $[15,16]$ than those achieved using for example cathodic arc evaporation [17-19]. Therefore, in order to demonstrate the viability of HiPIMS for tailor-made a-C thin film growth, the development of new strategies is required.

For metal-oxide thin film growth, the ability of HiPIMS to generate large ionized fluxes not only facilitates a control over film properties; it also provides efficient means for controlling the process conditions especially when the film growth is carried out in a reactive atmosphere (e.g. $\mathrm{Ar}+\mathrm{O}_{2}$ ) [20]. The energetic ion bombardment lead phase control and synthesis of crystalline compound thin films at lower growth temperatures has been demonstrated by HiPIMS [21,22]. The technique has also shown to provide stable operating conditions during reactive sputter deposition of stoichiometric compound thin films with a possibility to achieve higher growth rates than those achieved using reactive DCMS [23]. While considerable research has been carried out for understanding the HiPIMS process and demonstrating its potential for being a viable magnetron sputtering based method for high quality metallic film growth, there are still limited studies on reactive HiPIMS discharge characteristics. Understanding the reactive HiPIMS discharge properties will enable us to synthesize compound thin films for new and challenging applications.

\subsection{Aim of the thesis}

The aim of the thesis is to develop HiPIMS-based strategies to address the issues that are encountered in carbon-based thin film growth as well as to contribute to the fundamental understanding of reactive HiPIMS discharges of metal-oxides and synthesize metaloxides thin films for highly demanding applications. For the case of carbon-based films 
the development of the new strategies is based on designing new discharges by controlling gas composition and power schemes. This is facilitated by combining plasma diagnostics, ex situ film characterization and simulations. For the case of oxides understanding is achieved by using real time plasma diagnostics. For metal-oxide thin film growth, the aim is achieved by carrying out investigations on the reactive HiPIMS discharge characteristics by employing most commonly used material systems (Ti-O and Al-O), extending the investigations further to multicomponent systems (Al-Si-O) and synthesizing metal-oxide thin films $\left(\mathrm{TiO}_{2}, \mathrm{Al}-\mathrm{Si}-\mathrm{O}\right)$ that are relevant for highly demanding applications.

\subsection{Outline}

The introductory chapters preceding the appended papers are in the following sequence: First, a chapter is dedicated to basic plasma physics that is followed by an overview of the sputtering based methods that also includes a discussion on thin film growth. In succeeding chapters, material systems, research strategies and experimental details concerning the work presented in the appended papers are discussed. The introduction is concluded with the summary of the results presented in the appended papers. 


\section{Chapter 2}

\section{Basic Plasma Physics}

\subsection{Introduction}

The term plasma was first coined by Irving Langmuir in 1928 and it describes a highly ionized state of matter which is collectively charge neutral (often termed as quasi-neutral) [24]. A plasma consists of ions, electrons and neutral atomic and molecular species and it exhibits a collective behavior in presence of external electric and magnetic fields. The bulk of the plasma contains almost equal amounts of negative and positive particles, i.e. ions and electrons $\left(n_{i}=n_{e}=n_{0}\right)$ [24]. A plasma can be created by heating up a gas until the electrons from its freely moving atoms are released i.e. a gas breakdown occurs, to give a collection of randomly moving ions and electrons. The degree of ionization of the discharge gas commonly describes whether a plasma is weakly ionized or highly ionized [24].

Plasmas can also be classified as high temperature (hot) and low temperature (cold) plasmas $[1,24]$. Often a hot plasma is almost fully ionized, whereas a cold plasma may have $\sim 1 \%$ gas ionization [24]. Examples of high temperature plasmas include fusion plasmas both inside stars as well as man-made in a reactor, and they are characterized by thermal equilibrium among their constituents. Gas discharge plasmas, such as those used in material synthesis, are usually regarded as low-temperature (and also low pressure) and non-thermal plasmas [24]. Ions, electrons and neutral atomic and molecular species in such plasmas are not in thermal equilibrium. Electrons being lighter and hence easily accelerated by external fields, possess high temperatures as compared to the other heavy plasma constituents. For example, one often finds that neutral discharge gas is at room temperature, whereas the electrons reach several thousand degrees Kelvin. Through momentum exchange collisions it is however possible to equalize the different 
temperatures. In such a way a thermal equilibrium among the plasma constituents can be attained by, for example increasing the discharge gas pressure, since it results in an increased amount of collisions [24,25].

\subsection{Plasma for Material Synthesis}

The plasma for material synthesis by PVD is usually created by means of an electrical discharge of an inert gas. This is achieved by introducing the inert gas (typically Ar) into the process chamber (see Fig. 1), which is evacuated to a certain base pressure (the base pressure for the experiments that are concerned to this thesis was below $10^{-4} \mathrm{~Pa}$ ). The process chamber is equipped with two electrodes acting as a cathode and an anode. Usually a negative potential is applied to the target (the term is typically used in sputtering for source material) which is mounted onto a magnetron (see sec. 3.2), to serve as the cathode while the walls of the chamber serve as the anode. The potential difference between the cathode and the anode will give rise to electric fields that can accelerate charged particles, which is crucial for transferring the neutral discharge gas to a plasma. The gas breakdown is initiated by an inelastic collision between a free electron (which might be present due to cosmic radiation or thermal energy) and a neutral gas atom when the former is accelerated under the influence of the generated external electric fields to an energy above the ionization energy of the neutral gas (about $15.76 \mathrm{eV}$ in the case of Ar) [26]. In this way, the inelastic collisions give rise to the ionization as well as excitation of the gas atoms through the processes [27],

$$
\begin{aligned}
& \mathrm{Ar}^{0}+\mathrm{e}^{-} \rightarrow \mathrm{Ar}^{+}+2 \mathrm{e}^{-} \\
& \mathrm{Ar}^{*}+\mathrm{e}^{-} \rightarrow \mathrm{Ar}^{+}+2 \mathrm{e}^{-}
\end{aligned}
$$




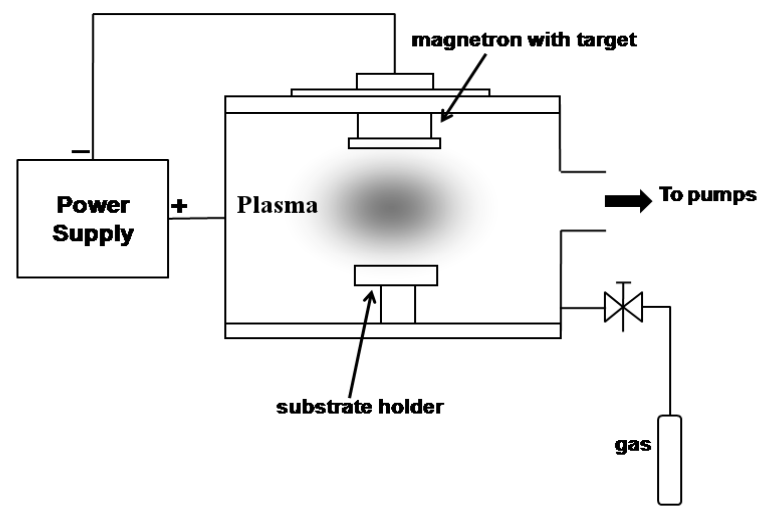

Figure 1. An schematic of a sputter deposition chamber. The target is clamped onto the magnetron which is mounted on the lid of the chamber. The target serves as the cathode while the chamber walls are made as the anode. An inert gas is let in through the leak valve and a plasma is created. The substrates for film deposition are placed on the substrate holder.

Each ionizing collision will result in two free electrons, which will also take part in the ionization of the gas atoms provided that they possess high enough kinetic energy. The ionized gas atoms, such as $\mathrm{Ar}^{+}$ions in this case, will be accelerated towards the negatively charged cathode and thereby ejecting the target atoms (through the process of sputtering, as described in chapter 3) along with the secondary electrons from the target surface. This process eventually results in a cascade of free electrons and ions, which finally leads to the gas breakdown. A continuous supply of the secondary electrons ensures that enough $\mathrm{Ar}^{+}$ions are produced to generate again, during the process of sputtering, enough secondary electrons which can compensate for the loss of the charged particles through the diffusion to the walls. The overall result is a self-sustained plasma discharge. The de-excitations during the whole process result in the emission of radiation and hence the discharge is termed as glow discharge [3]. Depending on the applied potential and the resulting discharge current, a plasma discharge can be divided into 
various regimes [3]. The process of sputtering, which is the prime focus of this work, belongs to the subdivision of the glow discharge which is called abnormal glow. In this regime, the discharge voltage and current density increase with increasing the discharge power until the ion bombardment covers the whole surface of the target. Increasing the power further leads to the arc discharge regime, which is characterized by an extremely high current density at the target surface which in turn gives rise to plasma density in the order of $10^{21} \mathrm{~m}^{-3}[3]$.

As described earlier, a plasma is considered as quasi-neutral however, this attribute is mainly associated with the bulk of the plasma - as is the case with most of the plasma properties. Some deviations such as charge imbalance may occur at the plasma boundaries where the plasma interacts with other surfaces, such as the chamber walls. This is due to the fact that the electrons being lighter are more mobile than ions and therefore diffuse faster to the walls thereby leaving the bulk plasma at a higher potential (which is called plasma potential) as compared to the grounded chamber walls. Typically, the plasma potential is a couple of volts [2]. In addition, any other isolated electrode immersed in the plasma will be at slightly negative potential (floating potential) as compared to the ground, which is also an effect of the faster electrons. Overall, this means that at the interface where the plasma interacts with any other surface, there is a region where ions will outnumber the electrons. This region is called plasma sheath [2,3]. A plasma sheath is therefore a non-neutral region in contrast to the bulk of the plasma. The potential profile of a continuous plasma discharge indicating the plasma sheaths is depicted in Fig. 2. 


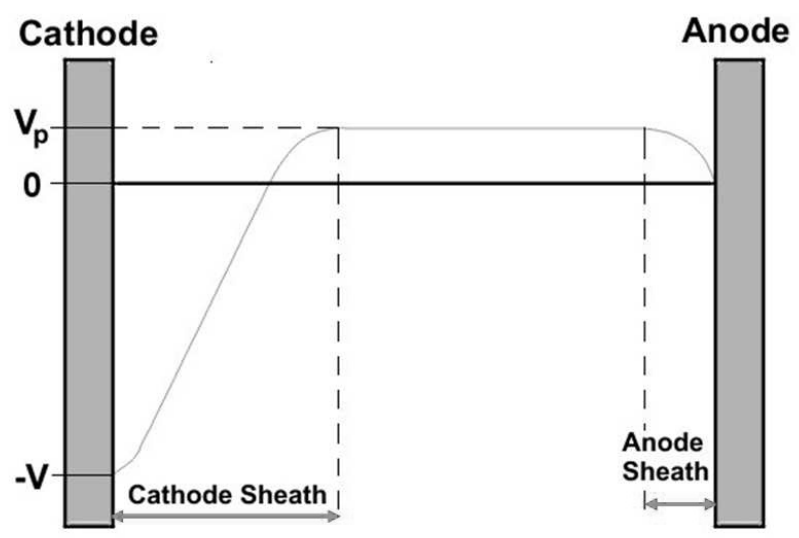

Figure 2. An schematic representation of the cathode and anode sheaths in a DC plasma discharge. The cathode represents the magnetron which is biased with potential $-V$ and the anode represents the chamber walls whereas $V_{p}$ is the plasma potential. (After M. Ohring [1].)

The sheath thickness is expressed in terms of a characteristic plasma parameter which is called the Debye length, $\lambda_{D_{e}}$, and it is given as [24],

$$
\lambda_{D_{e}}=\left(\frac{\varepsilon_{0} T_{e}}{e n_{0}}\right)^{1 / 2}
$$

Here $\varepsilon_{0}$ is the electric permittivity constant, $T_{e}$ is the electron temperature, $e$ is the elementary charge and $n_{0}$ is the plasma density under the equilibrium condition $\left(n_{\mathrm{i}}=n_{\mathrm{e}}=\right.$ $n_{0}$ ). The Debye length is the length scale over which a significant departure from charge neutrality can be maintained [24].

It has been discussed earlier that in low-temperature gas discharge plasmas $T_{e}$ is higher than the ions and neutral atoms temperatures (here denoted as $T_{i}$ and $T_{g}$ respectively). The electron energy distribution function (EEDF) in such a plasma discharge is nonMaxwellian (often bi-Maxwellian) [2]. This means that the EEDF consists of two 
electron populations, a low-energy population (called cold electron population) and a high-energy population (called hot electron population). Usually the average temperatures of the cold and hot electron populations, denoted as $T_{e_{-} \text {cold }}$ and $T_{e_{-} \text {hot }}$ respectively, are used as the representative and characteristic parameters for the respective populations. An example of such an EEDF from a C-HiPIMS discharge is presented in Fig. 3.

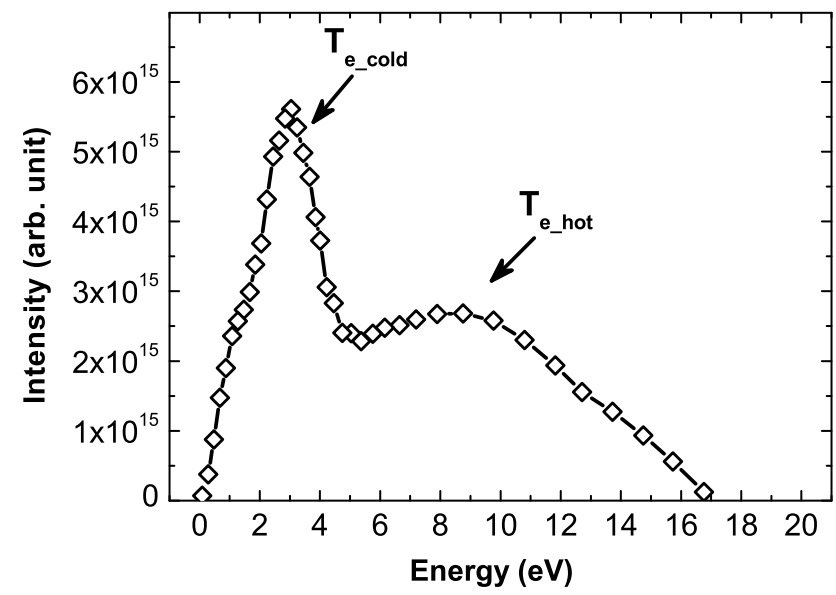

Figure 3. An EEDF from a Ne-HiPIMS discharge of carbon, showing two distinct electron populations (cold and hot). The EEDF was obtained by performing Langmuir probe measurements (see Sec. 5.11).

From such an EEDF, the electron density $n_{e}$ can also be determined. $T_{e}$ and $n_{e}$ in a plasma discharge are dependent on the type of the buffer gas used, chamber geometry as well as process parameters and can be affected by for example, sputtered material vapor and presence of a reactive gas (such as $\mathrm{O}_{2}, \mathrm{~N}_{2}, \mathrm{C}_{2} \mathrm{H}_{2}$ ). In the following sections, a brief discussion on the effect of the gas atmosphere on the ionization processes with respect to changes in $n_{e}$ and $T_{e}$ is presented. 


\subsection{Plasma properties and gas composition}

\subsubsection{Effect of change of buffer gas}

Owing to different ionization/excitation energies and cross sections, different $n_{e}$ and $T_{e}$ result from using different buffer gases. $E_{i z}$ of the buffer gas sets the $T_{e}$ in a plasma discharge [27]. Higher $E_{i z}$ buffer gas such as Ne provides a higher $T_{e}$ as compared to commonly used Ar, given that $n_{e}$ is the same (a larger power will be required in order to produce the same $n_{e}$ using $\mathrm{Ne}$ as with Ar) [27]. Higher $T_{e}$ means an increased ionization efficiency in discharges where electron impact ionization is the dominating ionization mechanism (high plasma density discharges such as HiPIMS) [28]. In paper I, plasma properties of C-HiPIMS discharges were investigated under different gas atmosphere by measuring $n_{e}$ and $T_{e}$. The gas atmosphere consisted of a mixture of $\mathrm{Ar}$ and $\mathrm{Ne}$ where $\mathrm{Ne}$ content was varied to analyze the influence of change of $E_{i z}$ on $n_{e}$ and $T_{e}$. Fig. 4 shows the results from the study where electron temperatures from cold and hot electron populations (see Fig. 3) are found to increase with an increase of the Ne content in the gas mixture.

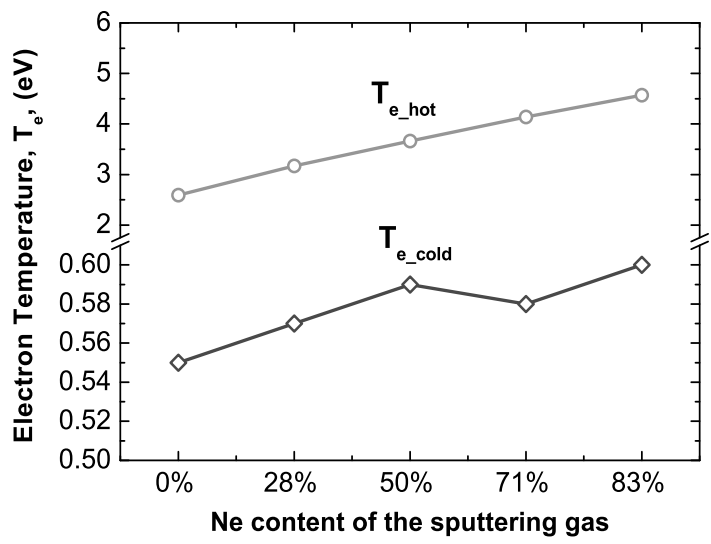

Figure 4. Electron temperatures ( $T_{e_{-} \text {hot }}$ and $\left.T_{e_{-} \text {cold }}\right)$ from a C-HiPIMS discharge containing Ar+Ne gas atmosphere as a function of the Ne content of the mixture. The electron temperatures were measured by employing a Langmuir probe. 


\subsubsection{Reactive gas atmosphere}

In plasma-based thin film deposition, gas atmosphere consisting of a reactive gas (such as $\mathrm{O}_{2}, \mathrm{~N}_{2}, \mathrm{C}_{2} \mathrm{H}_{2}$ ) mixed with a buffer gas is commonly used, such as for compound thin film deposition. The presence of a reactive gas brings about various interactions in addition to ionization; such as rotational and vibrational excitations, dissociation of molecular gaseous species etc. Depending on their cross sections and energy thresholds, these interactions can affect the ion generation by cooling down the plasma electrons. It has been shown that total energy losses per electron-ion pair created (which takes into account ionization, excitation as well as scattering interactions) for $T_{e}<7 \mathrm{eV}$ (close to the $T_{e}$ expected for bulk plasma electrons) are higher for $\mathrm{O}_{2}$ and $\mathrm{N}_{2}$ as compared to $\operatorname{Ar}$ [29]. The higher losses are attributed to losses due to dissociation as well as rotational and vibrational excitations. This suggests that the ion density in an $\mathrm{Ar}+\mathrm{O}_{2}$ discharge is likely to be lower compared to an $\mathrm{Ar}$ discharge. In an $\mathrm{Ar}+\mathrm{O}_{2}$ discharge, the inelastic interactions of plasma electrons with $\mathrm{O}_{2}$ will produce oxygen ions through direct and/or dissociative ionization processes. Since $E_{i z}$ of $\mathrm{O}_{2}(12.06 \mathrm{eV})$ [30] is lower than that of $\mathrm{Ar}$ $(15.75 \mathrm{eV})$ therefore oxygen ion generation is also expected. The reactive gas ion generation affects the plasma chemistry as well as discharge characteristics such as discharge current and discharge voltage are also influenced by the reactive gas ion fluxes (see sec. 3.4.2). These effects for reactive HiPIMS processes of Ti-O, Al-O and Al-Si-O have been investigated in paper $\mathbf{V}$ ( $\mathrm{Ti}-\mathrm{O}, \mathrm{Al}-\mathrm{O}$ ) and paper $\mathbf{V I}$ ( $\mathrm{Al}-\mathrm{Si}-\mathrm{O})$.

Mixing other reactive molecular gases such as hydrocarbon precursor gases (e.g. $\mathrm{C}_{2} \mathrm{H}_{2}$ ) with an inert gas during the process of film deposition is likely to affect the discharge properties in a similar manner however; the plasma chemistry in this case is more complicated as compared to for example $\mathrm{Ar}+\mathrm{O}_{2}$ discharge. Considering electron impact induced excitation, dissociation and ionization of hydrocarbon species (here we take $\mathrm{C}_{2} \mathrm{H}_{2}$ as an example), various reactions resulting in different product species are possible [31]. These reactions along with their threshold energies are outlined in Table I. $E_{i z}$ (11.4 $\mathrm{eV}$ ) of $\mathrm{C}_{2} \mathrm{H}_{2}$ is lower than Ar while its electron impact ionization cross section is about twice as higher $\left(24 \times 10^{-17} \mathrm{~cm}^{-2}\right.$ at $\left.25 \mathrm{eV}\right)$ [30] therefore large amounts of $\mathrm{C}_{2} \mathrm{H}_{2}{ }^{+}$ions are expected in the discharge. Also, the dissociation and dissociative ionization interactions result in the $\mathrm{H}$ generation therefore these discharges are abundant in atomic $\mathrm{H}$. In paper 
II, the discharge characteristics of an $\mathrm{Ar}+\mathrm{C}_{2} \mathrm{H}_{2}$ discharge and its influence on a-C film growth are investigated by assessing the structural properties of the resulting films.

In Sec. 2.3.1 the effects of change of buffer gas on the plasma parameters were discussed where it was shown that replacing Ar with $\mathrm{Ne}$ increases the $T_{e}$ in the discharge (Fig. 4) which in turn enhances the ionization efficiency of the sputtered C. In hydrocarbon based discharges such a change of buffer gas, is likely to enhance the ionization as well as dissociation and vibrational excitations of hydrocarbon molecules. From the discharge properties as well as film growth perspectives, the change of plasma chemistry may become significant. This effect of change of buffer gas on discharge characteristics and aC film properties is investigated in paper III by using $\mathrm{Ar} / \mathrm{Ne}+\mathrm{C}_{2} \mathrm{H}_{2}$ based HiPIMS discharges.

Table I: Commonly observed electron impact induced reactions along with their threshold energies in low-pressure $\mathrm{C}_{2} \mathrm{H}_{2}$ containing plasma discharges. The first ionization thresholds for Ar, $\mathrm{C}$ and $\mathrm{H}$ are 15.75, 11.26 and $13.59 \mathrm{eV}$, respectively [31].

\begin{tabular}{|c|c|c|}
\hline Reaction & Threshold Energy (eV) & Type of Reaction \\
\hline$C_{2} \mathrm{H}_{2}+e^{-} \rightarrow \mathrm{C}_{2} \mathrm{H}_{2}^{*}+e^{-}$ & $0.09-0.41$ & Vibrational Excitation \\
\hline $\mathrm{C}_{2} \mathrm{H}_{2}+e^{-} \rightarrow \mathrm{C}_{2} \mathrm{H}+\mathrm{H}+e^{-}$ & 7.5 & Dissociation \\
\hline $\mathrm{C}_{2} \mathrm{H}_{2}+e^{-} \rightarrow \mathrm{C}_{2} \mathrm{H}_{2}^{+}+2 e^{-}$ & 11.4 & Ionization \\
\hline $\mathrm{C}_{2} \mathrm{H}_{2}+e^{-} \rightarrow \mathrm{C}_{2} \mathrm{H}^{+}+\mathrm{H}+2 e^{-}$ & 16.5 & Dissociative Ionization \\
\hline $\mathrm{C}_{2} \mathrm{H}_{2}+e^{-} \rightarrow \mathrm{C}_{2}^{+}+\mathrm{H}_{2}+2 e^{-}$ & 17.5 & Dissociative Ionization \\
\hline $\mathrm{C}_{2} \mathrm{H}_{2}+e^{-} \rightarrow \mathrm{H}^{+}+\mathrm{C}_{2} \mathrm{H}+2 e^{-}$ & 18.4 & Dissociative Ionization \\
\hline $\mathrm{C}_{2} \mathrm{H}_{2}+e^{-} \rightarrow \mathrm{C}^{+}+\mathrm{CH}_{2}+2 e^{-}$ & 20.3 & Dissociative Ionization \\
\hline $\mathrm{C}_{2} \mathrm{H}_{2}+e^{-} \rightarrow \mathrm{CH}^{+}+\mathrm{CH}^{-}+2 e^{-}$ & 20.6 & Dissociative Ionization \\
\hline
\end{tabular}




\subsection{Ionization of the Sputtered Material}

As we have discussed in previous sections, $T_{e}$ and $n_{e}$, are important in establishing how the plasma constituents interact with each other. In the plasma chemistry many mechanisms are working in parallel, which means that these two parameters are also important in determining dominating reactions through which the ionization of the sputtered material occurs. In a sputtering plasma, the most common ionizing mechanisms for sputtered material are, direct electron impact ionization, electron impact ionization of excited sputtered atoms and the ionization via the interaction with excited sputtering gas atoms (also called Penning ionization). These mechanisms are respectively represented as [27],

$$
\begin{gathered}
\mathrm{M}^{0}+\mathrm{e}^{-} \rightarrow \mathrm{M}^{+}+2 \mathrm{e}^{-}, \\
\mathrm{M}^{*}+\mathrm{e}^{-} \rightarrow \mathrm{M}^{+}+2 \mathrm{e}^{-}, \\
\mathrm{M}^{0}+\mathrm{G}^{*} \rightarrow \mathrm{M}^{+}+\mathrm{G}^{0}+\mathrm{e}^{-} .
\end{gathered}
$$

where $\mathrm{M}$ and $\mathrm{G}$ respectively represent the sputtered and sputtering gas atoms.

Plasma discharges with high values of $n_{e}$ are dominated by electron impact ionization (processes in relation 2.4 and 2.5) while the low $n_{e}$ discharges are dominated by Penning ionization (process in relation 2.6) [27]. This is demonstrated in Fig. 5 for the sputtering discharge of Al using Ar [27]. 


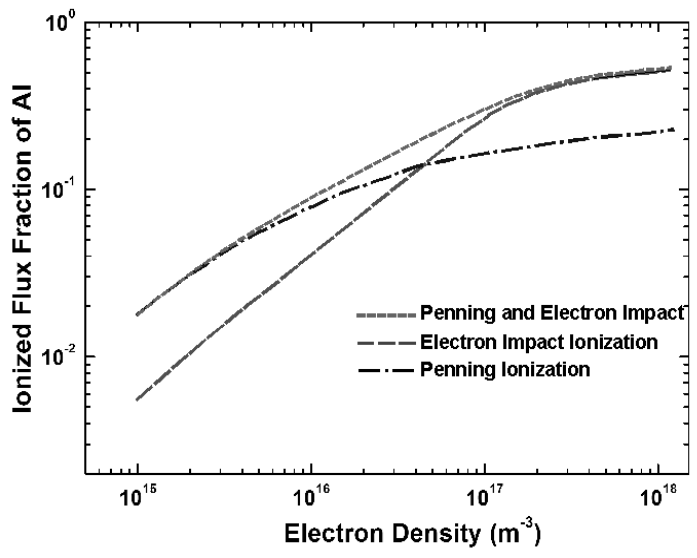

Figure 5. The process of ionization of sputtered Al at 36 mTorr of Ar gas pressure showing the region of dominance for electron impact and Penning ionization processes. (After J. Hopwood [27].)

Fig. 5 also demonstrates that a higher ionized fraction for the sputtered material is obtained with increased $n_{e}$. This is a general trend for sputtered materials however, the absolute number of the ionized fraction varies with the material dependent cross sections for ionizing reactions. Metals are readily ionized with $n_{e}$ in the range of $10^{16}$ to $10^{19} \mathrm{~m}^{-3}$ while the ionized fraction for non-metals such as carbon is low in this plasma density region. One of the factors for the low ionized fraction for the case of non-metals is their higher $E_{i z}$ values as compared to metals (for example, $E_{i z}$ for $\mathrm{C}$ is $11.26 \mathrm{eV}$ while for $\mathrm{Al}$ it is $5.98 \mathrm{eV}$ ). The dependence of the ionized fraction of the sputtered material on the plasma density is demonstrated in Fig. 6 for various materials [27]. 


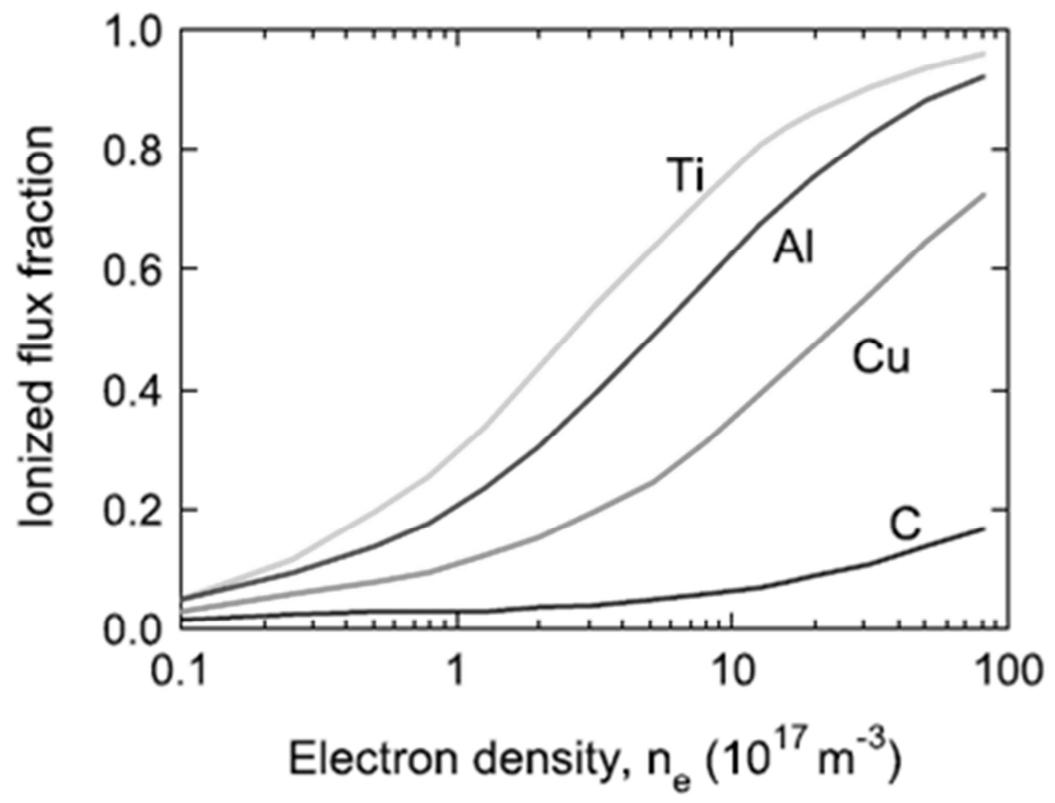

Figure 6. The ionized flux fraction dependence on plasma density for different materials. (After J. Hopwood [27].)

The dependence of the degree of ionization of the sputtered material on $T_{e}$ and $n_{e}$ can also be understood by looking at the mean ionization length of a sputtered atom, which is the average distance the sputtered atom travels before it is ionized in a plasma discharge [28]. For the electron impaction ionization, the mean ionization length (here denoted as $\lambda_{m i z}$ ) of the sputtered atom can be expressed as [28],

$$
\lambda_{\text {miz }}=v_{s} /\left(k_{\text {miz }} n_{e}\right)
$$

where $v_{s}$ is the velocity of the sputtered atom and $k_{m i z}$ is the rate constant for electron impact ionization which is expressed as,

$$
k_{\text {miz }}\left(T_{e}\right)=k_{0} \exp \left(-E_{0} / T_{e}\right) .
$$


The constants $E_{0}$ and $k_{0}$ are material dependent and they can be extracted from experiments or computer simulations [28,32].

The exponential nature of $k_{m i z}$ in Eq. 2.8 suggests that the degree of ionization of the sputtered material is more sensitive to changes in $T_{e}$ as compared to $n_{e}$. As an example, the $k_{\text {miz }}$ calculated using Eq. 2.8 for $T_{e}$ ranging from $1 \mathrm{eV}$ to $5 \mathrm{eV}$ and a constant value of $n_{e}$ for $\mathrm{C}$ is presented in Figure 7. It can be observed that a change of $T_{e}$ from $1 \mathrm{eV}$ to $5 \mathrm{eV}$ increases the $k_{m i z}$ by about 4 orders of magnitude.

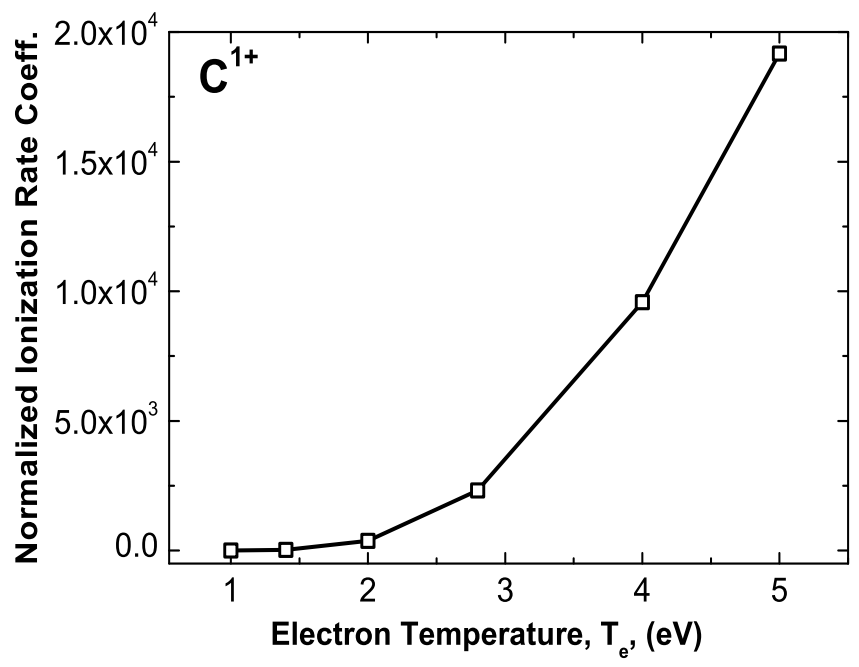

Figure 7. $k_{m i z}$ as a function of $T_{e}$ calculated for sputtered carbon using a constant value of $\boldsymbol{n}_{e}$.

Eq. 2.7 shows that an increase in both, $T_{e}$ and $n_{e}$ will result in the decrease in the $\lambda_{\text {miz }}$ which implies that the probability of the ionization of the sputtered material will increase. In the light of this discussion, considering the results presented in Fig. 4 where an increased $T_{e}$ is shown to be obtained when increasing Ne content in the mixture of $\mathrm{Ar}+\mathrm{Ne}$ 
in a HiPIMS discharge of $\mathrm{C}$, it can be inferred that the sputtered $\mathrm{C}$ atoms will have lower mean ionization lengths in a Ne-based HiPIMS discharge as compared to Ar-based HiPIMS discharge. Using $T_{e}$ plotted in Fig. 4 and a constant value of $n_{e}$ in Eq. 2.7 through Eq. 2.8, the $\lambda_{\text {miz }}$ values are calculated for sputtered C. The result is presented in Fig. 8 which manifests about an order of magnitude decrease in $\lambda_{\text {miz }}$ and hence significant increase in ionization probability for sputtered $\mathrm{C}$ when the sputtering gas atomosphere is dominated by $\mathrm{Ne}$.

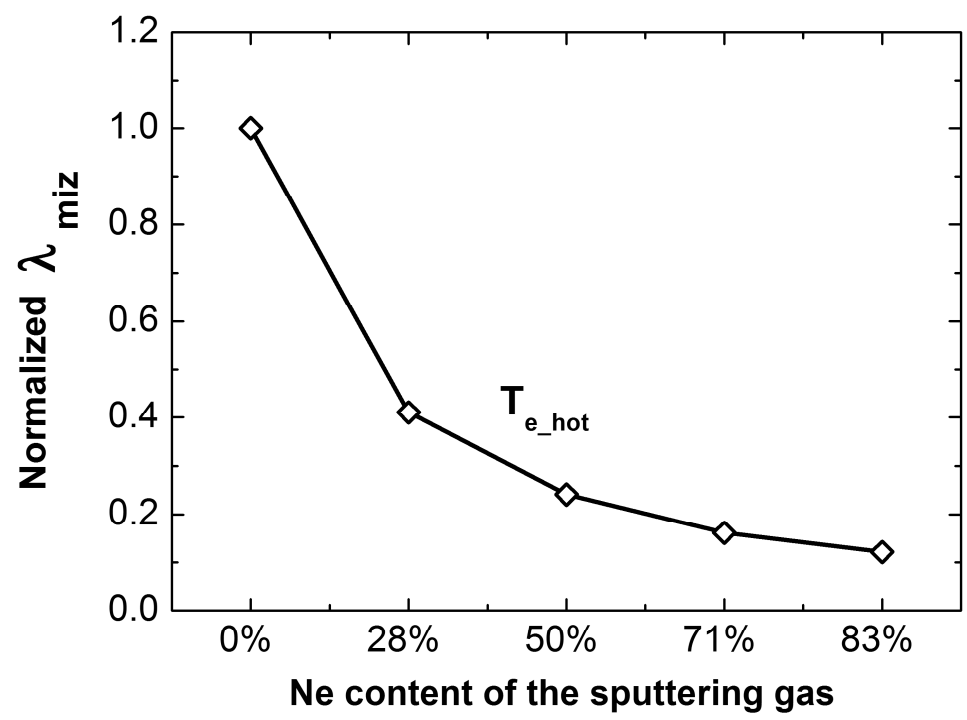

Figure 8. $\lambda_{m i z}$ of sputtered carbon as a function of Ne content of the sputtering gas mixture of Ar+Ne. 


\section{Chapter 3}

\section{Thin Film Deposition Processes}

Thin film deposition in this thesis has been performed using magnetron sputtering based methods. In the following sections, a brief introduction of process of sputtering, magnetron sputtering as well as its relevant variants is presented. A section where thin film growth is discussed is also included.

\subsection{Sputtering}

Sputtering is a physical process of ejecting target atoms (source material) by means of an incident energy and momentum transfer [1,2]. In a plasma-based sputtering process, the incident energy is supplied through collisions between the ions from the plasma and the target atoms. Ions from the plasma reach to the target surface under the influence of electric fields that are generated by applying a negative potential to the target. Upon the impact of the ions on the target surface, various ion-solid surface interactions occur. On the basis of the energy of the incident ions, the process of sputtering can occur in three regimes namely single knock-on (low energy regime, $<1 \mathrm{keV}$ ), linear cascade (moderate energy regime, $1-50 \mathrm{keV}$ ) or spike (high energy regime, $>50 \mathrm{keV}$ ). These interactions are depicted in Fig.9 [1]. 


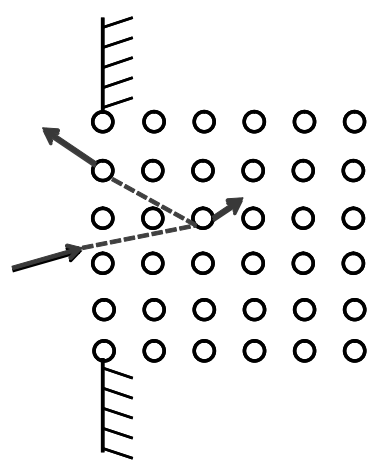

a)

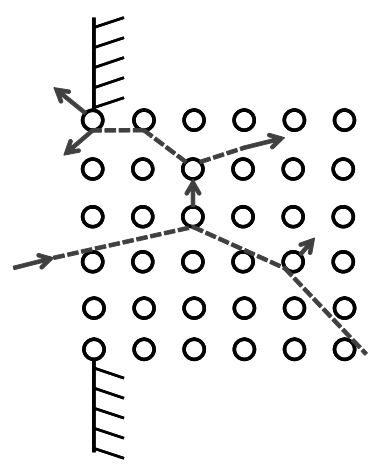

b)

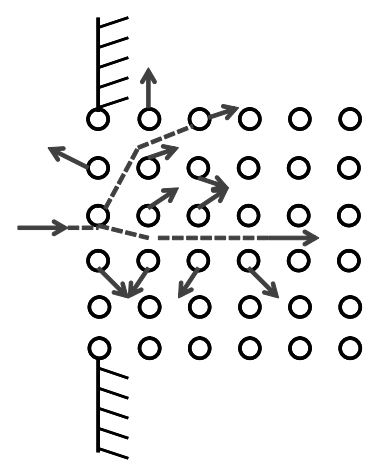

c)

Figure 9. Energy regimes of sputtering: a) Single knock-on (low energy), b)

Linear cascade (moderate energy) and c) Spike (high energy). (Adapted from [33].)

The amount of source material sputtered from the target is dependent on the bombarding ion species, their energy and angle of incidence as well as target material. A relevant quantity that is used for expressing the relationship between these parameters is sputtering yield, $Y$, which is defined as [25]:

$$
Y=\frac{\text { average number of sputtered target atoms }}{\text { number of incident ions }}
$$

For the energy range such as that valid for the process of sputtering $(<1 \mathrm{keV})$, a linear relationship between the sputtering yield and the energy of the projectile is found to be a sufficient approximation. The sputtered target atoms follow the Thomson energy distribution whereas their spread can be approximated with a cosine distribution [34]. The sputtered atoms traverse through the bulk plasma and thereby condense onto all surfaces in the reactor. Through their course, the sputtered atoms suffer elastic collisions with background gas atoms and are subsequently thermalized [1,27,34]. A fraction of them can also be ionized due to the inelastic collisions with electrons as described in Sec. 2.4. 
During the process of sputtering, besides the target atoms, electrons from the target surface are also ejected. These electrons are termed as secondary electrons [2]. The ejected secondary electrons are accelerated away from the target by the sheath potential (cathode sheath, see Sec. 2.2) reaching to the bulk plasma where they take part in the ionization of the sputtering gas atoms thereby helping the discharge to sustain. Similar to the sputtering yield, secondary electron emission is also dependent on the bombarding ion species and energy carried by them as well as on the composition of the target material. For low bombarding energy regime $(<1 \mathrm{keV})$, secondary electron emission coefficient can be written as [35];

$$
\gamma_{S E}=0.032\left(0.78 E_{i z}-2 \varphi\right)
$$

Here $\gamma_{S E}$ is the ion induced secondary electron emission co-efficient, $E_{i z}$ is the ionization potential of the bombarding ion and $\varphi$ is the work function of the target surface. Eq. 3.2 has been deduced by fitting the experimentally determined secondary electron emission for various metals.

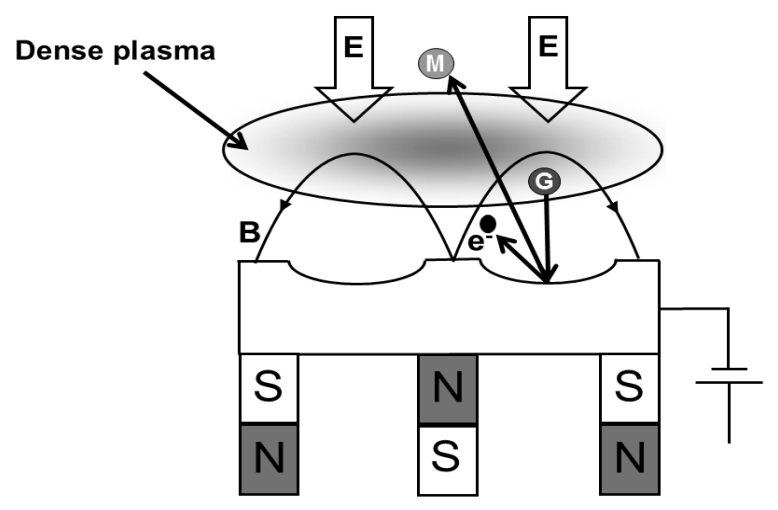

Figure 10. Schematic showing the concept of magnetron sputtering. Here $G$ is representing an incident sputtering gas ions whereas $M$ is the sputtered metal atom. 


\subsection{Magnetron Sputtering}

Typically, the amount of ejected secondary electrons is low $\left(\gamma_{S E} \sim 0.05-0.2\right.$ for most metals) [36,37] therefore to achieve an easier sustainability of the discharge it is desired that the ionization efficiency of the secondary electrons (ionizing events per electron) is enhanced [2]. This can be achieved by confining the secondary electrons in a region very close to the target surface. This is the principle of so-called magnetron sputtering, where the confinement of the electrons is achieved by using magnetic field (Fig. 10). This is commonly achieved by placing permanent magnets at the back of the target such that the magnetic field lines form a close loop thereby trapping the electrons. The effect of the electron confinement is the increased ionization efficiency and thereby an increased rate of sputtering. This also ensures an operation at reduced pressures as compared to diode sputtering where a high pressure is required to ignite as well as sustain a plasma discharge. The concept of a magnetron sputtering is illustrated in Fig. 10.
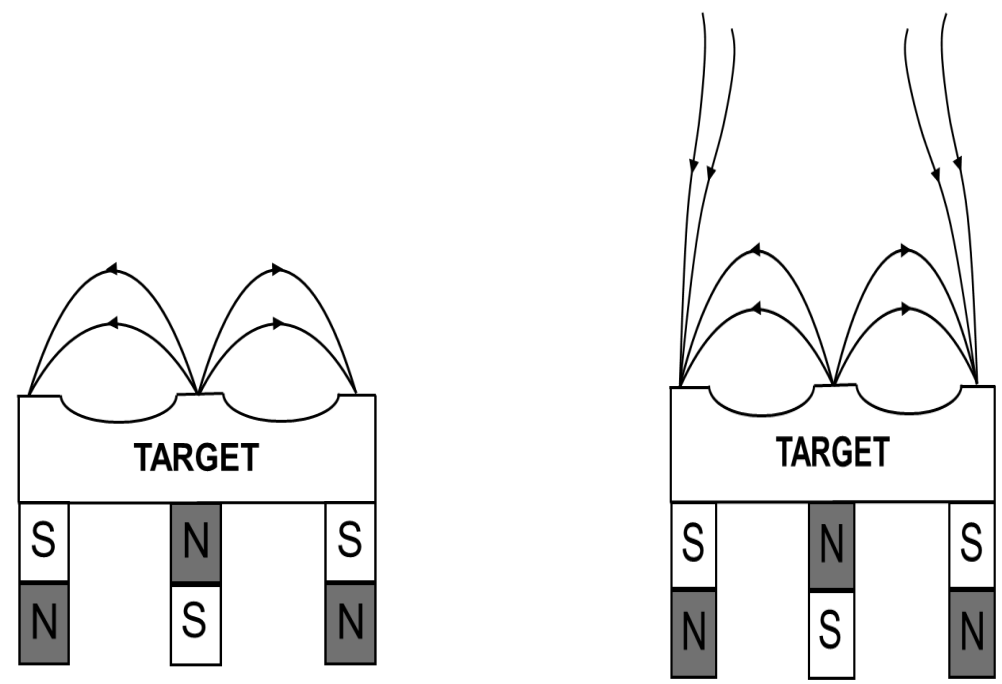

Figure 11. Schematic showing the balanced (left) and unbalanced (right) magnetic field configurations of a magnetron. 
Two different magnetic field configurations — balanced and unbalanced — are employed for a magnetron, Fig. 11. In a balanced magnetic field configuration, the strengths of the inner and outer magnetic pole pieces are the same and the magnetic field lines form (virtually) close loops. Such an arrangement provides efficient confinement of the secondary electrons close to the target surface. In an unbalanced magnetic field configuration, the strengths of the outer and inner magnets are not the same. For instance in the so-called type-II unbalanced magnetron (as shown in Fig. 11), outer magnets are made stronger than the inner magnets. This allows the magnetic field lines to open-up and extend in the chamber towards the substrate. The secondary electrons will follow the field lines dragging also the gas ions along with them thereby extending the plasma close to the substrate. This provides possibility to promote ion bombardment at the substrate (for example by applying a substrate bias potential) during the film growth which is beneficial for example for modifying the film properties.

\subsubsection{Direct Current Magnetron Sputtering}

One of the most common magnetron sputtering based method which is widely employed for the synthesis of thin films is DCMS. In DCMS, the target material is vaporized by applying a constant power while keeping the target power density in the order of a few $\mathrm{Wcm}^{-2}$, which is necessary to prevent overheating of the target [7]. The resulting target current densities are in the order of a few $\mathrm{mAcm}^{-2}[8,38]$. Such current and power densities provide plasma densities in the order of $10^{14}-10^{16} \mathrm{~m}^{-3}$ [8]. The sputtered target atoms which typically have energies in the order of few $\mathrm{eV}$ with energy tails of several tens of $\mathrm{eV}$ are not ionized to large degrees due to low plasma densities. The resulting ionized fraction of the sputtered metals in DCMS processes is of the order of few percent [39] and the majority of the depositing flux consists of neutral species. This means that the energetic deposition conditions which are essential for the modification of the film properties are difficult to achieve. Furthermore, the film deposition proceeds as line-ofsight deposition and uniform film growth on complex-shaped objects is difficult. As discussed before, by employing an unbalanced magnetron and by applying large negative bias potentials to the substrate, ion bombardment during the film growth can be promoted [1]. However, since the ionized fraction of the sputtered material is low, mainly sputtering gas ions (for example $\mathrm{Ar}^{+}$ions) are likely to reach to the substrate. For high 
substrate bias potentials, this can lead to the implantation of the sputtering gas ions into the films which may deteriorate the film quality for example by introducing stresses in the films.

\subsubsection{High Power Impulse Magnetron Sputtering}

As we have discussed in the previous section, an increased ionized fraction of the sputtered material is desired for the modification of the growing film and tailoring the film properties. The ionized fraction can be enhanced by increasing the plasma density (as discussed in Sec. 2.4) which in turn is dependent on the target power densities. Due to the limitation of heat-load on the target, this cannot be achieved using a constant power, such as using DCMS. In HiPIMS large plasma densities are achieved by applying the a high power to the target in the form of short pulses (pulse frequencies in the range of 100 $\mathrm{Hz}$ to $10 \mathrm{kHz}$ ) such that the duty cycle (pulse on time between 5-500 $\mu \mathrm{s}$ ) is kept low $(<5 \%)$ to avoid overheating thereby preventing the target damage. This enables an operation with typical peak power densities in the order of several $\mathrm{kWcm}^{-2}$ and target current densities of the order of several $\mathrm{Acm}^{-2}$ resulting in plasma densities in the order of $10^{18}-10^{19} \mathrm{~m}^{-3}$ which are 2-3 orders of magnitude higher as compared to DCMS [8$10,20]$.

The HiPIMS process conditions have been shown to facilitate high degree of ionization of the sputtered metals ( $90 \%$ for Ti) [40] as well as relatively higher energies of the sputter-ejected metal ions as compared to DCMS have been measured in HiPIMS processes [41]. High degree of ionization and energetic deposition fluxes have been shown to facilitate the synthesis of smoother and denser elemental and compound films with a control over their microstructure, phase composition, mechanical and optical properties [11,20,42]. Furthermore, uniform film deposition on complex-shaped substrate, improved film adhesion to the substrates as well as possibility of lowtemperature synthesis of thin films has also been demonstrated by HiPIMS $[12,21,43]$.

In this thesis, HiPIMS discharge characteristics and the effect of HiPIMS process conditions on the film growth have been investigated for elemental as well for reactively deposited compound thin films. A representative of the discharge characteristics of a HiPIMS process is its discharge current-voltage characteristic and many important 
aspects of the discharge can be inferred by analyzing for example; the resulting peak target voltage, shape and peak values of current waveforms etc. Typical current-voltage characteristic curve from a HiPIMS discharge are presented in Fig. 12. Several authors have studied the discharge current-voltage characteristics during a non-reactive as well as reactive HiPIMS process [44-46]. Lundin et al. [44] have discussed the HiPIMS discharge characteristics by considering the discharge current in three distinct phases; (I) plasma ignition followed by (II) a decay after passing a current maximum and (III) a steady-state regime as seen in Fig. 12.

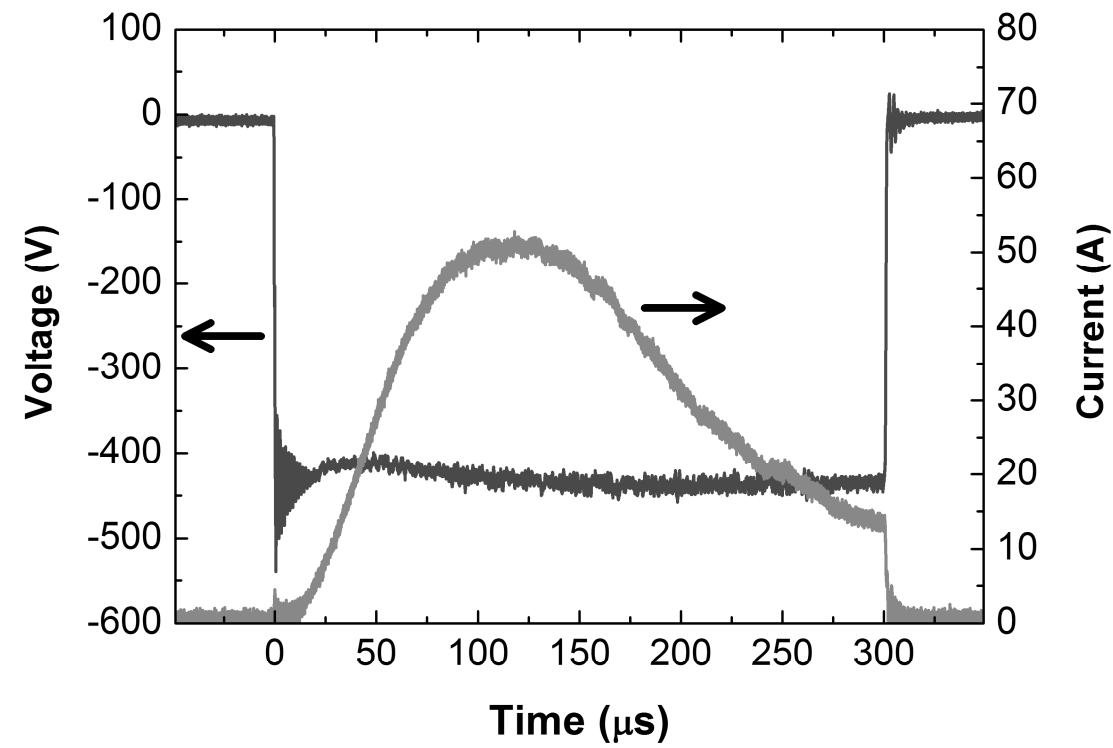

Figure 12. A voltage and current pulse recorded from a Ti Ar-HiPIMS discharge operated at $200 \mathrm{~W}$ of average power.

In the plasma ignition phase, initially the discharge current is constituted mainly by sputtering gas ions whereas the latter part of the phase is dominated by ionized sputtered atoms because a fraction of these may return back to the target (due to large applied negative voltages) and contribute to the discharge current. The decay after the peak current in the second phase occurs due to reduced gas density in front of the target. This is mainly caused by loss of sputtering gas atoms via ionization as well as due to 
rarefaction via collisions from the sputtered material flux. The steady-state phase essentially reflects DCMS-like plasma density and heat equilibrium regime which is observed for pulse on time $\left(\mathrm{t}_{\mathrm{on}}\right) \geq 200 \mu \mathrm{s}$.

The discharge current is essentially the sum of the ion and electron currents and it can be written as;

$$
I_{D}=I_{\text {ion }}+I_{\text {electron }}
$$

As discussed in Sec. 3.1, due to the ion bombardment on the target surface, emission of secondary electrons from the target surface occurs. These secondary electrons will also contribute to the discharge current. Therefore, the discharge current at the target surface can be written in the following form [47]:

$$
I_{D}=I_{\text {ion }}\left(1+\gamma_{S E}\right),
$$

where $I_{i o n}$ is the total ion current constituted by ionized species from the plasma. $\gamma_{S E}$, the secondary electron emission coefficient can be determined using Eq. 3.2.

The discharge characteristics of HiPIMS processes for carbon-based thin film growth have been investigated in paper III whereas for metal-oxide thin film growth, the investigations on the discharge properties are carried out in paper IV and $\mathbf{V}$.

\subsection{Reactive Magnetron Sputtering}

Reactive magnetron sputtering refers to the magnetron sputtering based method of film deposition where the gas ambient consists of a reactive gas (such as $\mathrm{O}_{2}, \mathrm{~N}_{2}$ ) that is either used alone or mixed with an inert gas [2,34]. Typically, the method is employed for compound film growth such as Al-O, Ti-N etc. Different approaches are employed for compound film synthesis such as film deposition performed using a compound target in either a pure inert or reactive gas ambient or compound film deposition carried out using for example a metallic target in a mixed inert gas and reactive gas ambient [34]. An 
example of the former is the synthesis of $\mathrm{Al}_{2} \mathrm{O}_{3}$ [48] thin films using an alumina target sputtered in an Ar gas ambient and an example of the latter is the synthesis of $\mathrm{TiO}_{2}$ thin films using a $\mathrm{Ti}$ target in a gas ambient of $\mathrm{Ar}+\mathrm{O}_{2}$ [22]. In this thesis, the approach of reactive sputter deposition has been employed for synthesizing a-C:H (paper II and III), Ti-O (paper IV) and Al-Si-O (paper VI) thin films.

During the process of reactive sputtering, a stepwise increase of the reactive gas flow into the process chamber initiates the formation of compound on all surfaces (target, chamber walls, substrate etc.) via chemisorption $[49,50]$. The compound formation depends on the reactive gas flow, surface coverage and the sticking coefficient of the reactive gas atoms. At the target surface, the compound formation is affected by the process of sputtering which will depend on the ion current density, sputtering yield of the compound as well as the target surface coverage [51]. Under low flow rates of the reactive gas, the target surface coverage by compound formation is small and the compound is over-sputtered by metal resulting in substoichiometric film growth at the substrate [49,51]. The partial pressure increase of the reactive gas in this condition is not significant. This mode is often referred to as metallic mode. At very high flow rates where the target surface is completely covered by the compound (poison/compound mode), the resulting films are stoichiometric however, owing to the low sputtering yield of the compound, low deposition rates are often observed. In the poison mode, there exists a linear relationship between the partial pressure of the reactive gas and the gas flow rate [49].

The transition from the metallic to compound mode is often abrupt and any operation within the transition zone is likely to result in an unstable process as well as hysteresis in the process parameters such as partial pressure of the reactive gas. The advantage of running at the transition zone is that stoichiometric thin films can be synthesized at higher deposition rates as compared to the compound mode. Process stability at the transition zone can be attained by controlling the target surface coverage i.e. reactive gas flow by employing a feedback system. Several methods are used that allow for controlling the reactive gas flow by monitoring for example the partial pressure of the reactive gas, discharge voltage or optical emission from the discharge [52]. 


\subsection{Reactive HiPIMS}

\subsubsection{Process stability}

HiPIMS provides possibilities of hysteresis-free reactive processes that can be operated at the transition zone without employing a feedback control system. The first reports on elimination/suppression of hysteresis in a HiPIMS process were presented by Wallin $e t$. al. using Al-O and Sarakinos et. al., using Zr-O [21,23] where both of these studies also presented a comparison with reactive DCMS processes. These studies reveal that a stable transition zone using HiPIMS is obtained which is a consequence of high instantaneous target erosion rates during the pulse (facilitated by high ion current densities) that lead to efficient target cleaning. Another factor that contributes to the process stability using a HiPIMS discharge is its inherent pulsing nature, which entails low reactivity at the target surface during the plasma-off state resulting in reduced target poisoning [20,53].

An important implication of the process stability at the transition zone is that stoichiometric compound films can be synthesized at higher growth rates compared to those achieved when the films are synthesized in the compound mode. Also it has been observed that reactive DCMS processes exhibit an unstable transition zone which implies that the process stability in reactive HiPIMS may allow for the compound film synthesis at rates comparable to those achieved using DCMS [23].

\subsubsection{Discharge characteristics}

As discussed in section 2.4.2, the introduction of a reactive gas into a discharge brings about interactions of plasma electrons with reactive gas species. In the case of molecular reactive gases $\left(\mathrm{O}_{2}, \mathrm{~N}_{2}\right.$ etc.), in addition to ionization other interactions such as dissociation as well as rotational and vibrational excitations will take place. Owing to large plasma densities, reactive HiPIMS discharges are likely to promote these interactions and more pronounced influence of reactive gas species on discharge characteristics and film properties is expected as compared to for example reactive DCMS. The dissociation interactions of reactive gas species can be beneficial for example for reactive processes that involve hydrocarbon gases (such as $\mathrm{C}_{2} \mathrm{H}_{2}, \mathrm{CH}_{4}$ ). HiPIMS discharge conditions in such a process can promote $\mathrm{H}$ and $\mathrm{C}$ extraction through electron impact induced interactions. Together with energetic ion bombardment, this can 
provide an efficient control over film composition and properties. The ionization of reactive gas species can also beneficially influence the discharge characteristics as well as film growth. Large fluxes of reactive gas ions $\left(\mathrm{O}^{+}, \mathrm{N}^{+}\right)$in Ti-O and $\mathrm{Cr}-\mathrm{N}$ [54] HiPIMS discharges have been previously measured where $\mathrm{O}^{+}$and $\mathrm{N}^{+}$ions have been found to exhibit significantly high energies (up to about $100 \mathrm{eV}$ ). We also measured energetic fluxes of $\mathrm{O}^{+}$ions in reactive HiPIMS discharges of different metal-oxides (Ti-O, Al-O, Al-Si-O). Fig. 13 shows an example of such an energy distribution function of $\mathrm{O}^{+}$ions measured in Al-O and Al-Si-O discharges.

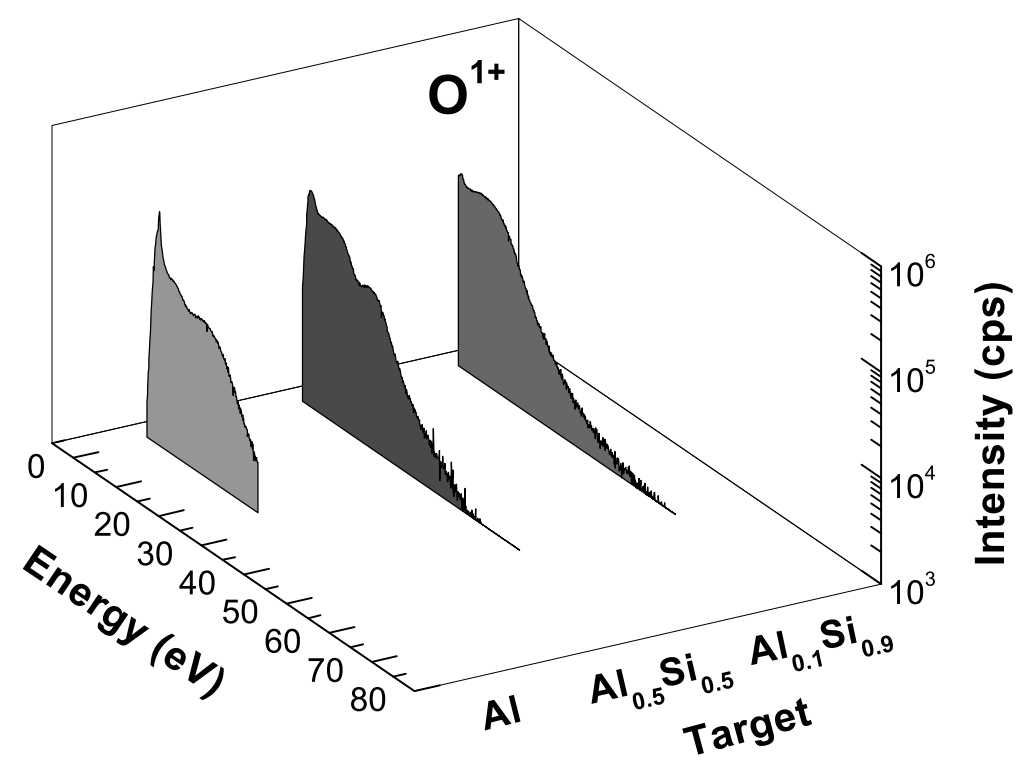

Figure 13. Energy distributions of $\mathrm{O}^{1+}$ ions measured using a mass spectrometer in the oxide modes of Al-O and Al-Si-O HiPIMS discharges under different target compositions. The discharges were operated at $50 \mathrm{~W}$ of average power that was obtained by using $50 \mu$ s pulses at a repetition rate of $500 \mathrm{~Hz}$.

The generation of large energetic ion fluxes of reactive gases as well as their enhanced dissociation in a reactive HiPIMS discharge can have its impact on plasma chemistry, target surface condition as well as on film growth. At the target surface, the measured discharge current exhibits striking differences in reactive HiPIMS processes as compared 
to its metal counterpart. As it is shown in Fig. 14, in reactive (compound) mode, the discharge current is characterized by a high peak value as well as the shape of the current waveform is different as compared to the metal mode. The observed differences in the discharge current between metal and oxide modes have been attributed to the generation of large ionized fluxes of reactive gas (such as $\mathrm{O}_{2}$ in this case) as well as effect of ion induced secondary electron emission coefficients. The discharge current behavior and its correlation to plasma chemistry and energetics as well as target surface conditions have been discussed for different metal-oxide systems (Ti-O, Al-O, Al-Si-O) in paper $\mathbf{V}$ and VI.

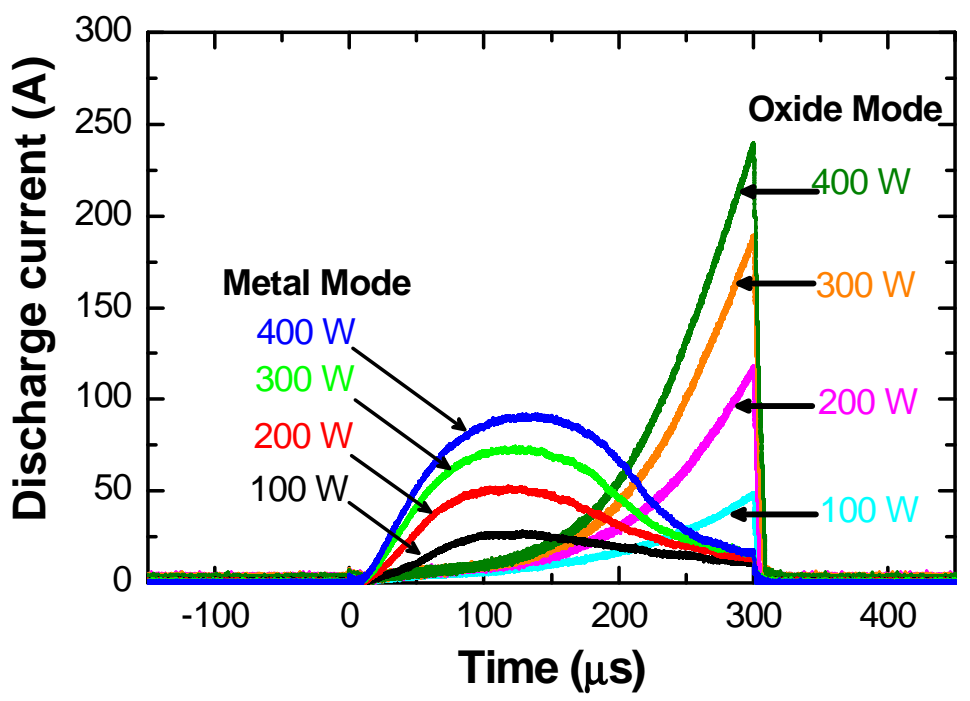

Figure 14. A HiPIMS voltage and current pulse recorded from an Ti-O discharge operated at $500 \mathrm{~Hz}, 300 \mu$ and $50 \mathrm{~W}$ of average power. 


\section{Chapter 4}

\section{Thin Films Growth and Materials Systems}

In the previous chapter we discussed the generation of vapor fluxes of the source material that is desired to be deposited as a thin film. In the subsequent sections, a discussion on the process of arrival of the vapor on a substrate and thin film formation is presented. The growth and state-of-the art of the thin film materials systems that have been used in this thesis is also briefly discussed.

\subsection{Thin Film Growth}

The vapor of the source material created during the process of sputtering reaches to the substrate where the arriving atoms condensate, leading to the growth of a thin film. The process of film growth goes through several stages. It starts with the adsorption of the arriving atoms (adatoms) which diffuse on the substrate surface to find energetically favorable sites and form two-dimensional cluster of atoms (nuclei). The formed nuclei grow as a result of a continuous addition of adatoms thereby resulting in a continuous film [55]. These processes are discussed below.

Upon reaching to the substrate, the arriving atoms experience the attractive potential of the substrate atoms and gain an energy which corresponds to the cohesive energy of the substrate material. This modifies the initial kinetic energy of the arriving atoms. The arriving atoms can adsorb to the substrate surface or re-evaporate back into the gas phase which depends on how much energy of the atoms is dissipated (in the form of substrate lattice vibrations i.e. phonons) during the collisions with the substrate. If the fraction of the total energy of an atom that is dissipated at the substrate is enough to place its total energy lower than its adsorption energy (which is some fraction of the cohesive energy), the atom sticks to the surface and adsorbs i.e. it becomes an adatom. The adatom can 
diffuse on the surface in a two-dimensional random walk during which the adatom jumps from one potential well of the surface to another. The mean square displacement or diffusion length for such a random walk is given as [55]:

$$
D=\frac{1}{4} l^{2} v
$$

where $l^{2}$ denotes the mean square distance that is covered in a single jump, $v$ the jump rate and $D$ is the surface diffusion coefficient.

The condensation and the diffusion of the adatoms on the surface of the substrate is largely dependent on their kinetic energy and flux as well as on the surface conditions i.e. surface chemistry, atomic structure and substrate temperature. For the case of high arrival rate of the film forming flux or low substrate temperatures, the diffusivity of the adatoms on the surface is limited [2]. The adatoms essentially do not have enough time to diffuse to the low-energy sites and they buried by subsequently arriving atoms and therefore the resulting thin films exhibit amorphous structures [2,56,57].

As discussed before, the formation of clusters leads to nucleation which refers to a stable state of the formed cluster. This means that the probability for these clusters to growth is higher than for them to dissociate. The growth of these clusters is classified in three different characteristics modes for crystalline (epitaxial) film growth. Frank-van der Merwe (F-M) or 2D layer-by-layer growth mode corresponds to the case of higher binding energies between adatoms and the substrate as compared to between adatom and adatom. The growth of metal on metal is an example of 2D growth mode. Another mode which is known as $3 \mathrm{D}$ or Volmer-Weber $(\mathrm{V}-\mathrm{W})$ growth mode refers to the growth mode where the adatoms are relatively strongly bound to each other than to the substrate. Examples of such a growth are metal film deposition on insulators or on contaminated substrates. The third growth mode which is known as Stranski-Krastanow growth mode is the combination of the F-M and V-W modes. In this case, initially the layer by layer growth occurs which is followed by $3 \mathrm{D}$ island growth. 
For conditions of non-epitaxial film growth far from equilibrium such as in the case of sputter deposition, the polycrystalline film growth becomes relevant. In this case, the continuous film growth is preceded by secondary nucleation or the so-called coalescence of initially formed nuclei and coarsening where the latter refers to the condition when island of lower energy per atom consume other islands consequently resulting in larger crystalline islands. This can also give rise to preferential crystalline orientation in some cases. After the coalescence and coarsening, the film growth proceeds with the columnar growth. The structure of these columns and hence the growing film largely depends on the energy which is provided to the growing film. The assessment of the film structure under different means of supplying this energy (such as growth temperature, energetic bombardment) is made in the so-called structure zone models (SZM). In such a model, microstructural evolution of the growing films in three distinct zones (zone I, zone II and zone III) is assessed based on the so-called homologous temperature $\left(T_{h}\right)$ which is the substrate temperature $\left(T_{s}\right)$ that is normalized to the melting temperature of the film material $\left(T_{m}\right)$ i.e. $T_{s} / T_{m}$. In zone I $\left(T_{h}<0.3\right)$, the films are grown far from the melting temperature and the diffusion of the adatoms is low. The resulting film exhibits structure based on fibrous columns that are separated by voids. At higher $T_{h}(0.3-0.5)$ of zone II, surface diffusion of the adatoms is high and the film structure consists of uniform columns that may extend to the whole film thickness. In between zone I and zone II, a transition (zone $\mathrm{T}$ ) has been described which is characterized by competitive grain growth and V-shaped columnar structure that is not extended to the whole film thickness leading to inhomogeneous grain structure. For further higher temperature the microstructure of the growing films is defined by zone III $\left(T_{h}>0.5\right)$ where the microstructure is characterized by large grains. In this case, bulk diffusion and recrystallization lead to dense film structures.

\subsection{Amorphous Carbon}

Amorphous carbon (a-C) can be grown in variety of different forms; from pure disordered structure to crystalline as well as in hydrogenated (often denoted as a-C:H) and hydrogen-free forms $[13,58,59]$. The versatility of the material stems from its different hybridization states i.e. $s p^{l}, s p^{2}$ and $s p^{3}$ bond configurations. In $s p^{l}$ configuration, two of the four valence electrons of a carbon atom form $\sigma$ (sigma) bonds 
directed along one plane (say x-plane) with its neighboring atoms, while the remaining two undergo a $\pi$ (pi) bond formation in y and $\mathrm{z}$ planes. In $s p^{2}$ bond coordination, three of the four valence electrons form $\sigma$ bonds with neighboring atoms in the plane while the fourth electron forms a $\pi$ bond, which is perpendicular to the $\sigma$ bond plane. This means that the interlayer bonding is based on weaker $\pi$ bonds. In $s p^{3}$ configuration, all four valence electrons enter into $\sigma$ bonds with neighboring atoms. Since the $\sigma$ bond is stronger as compared to $\pi$ bond, the a-C film which are rich in $s p^{3}$ bonds exhibit higher hardness than the one which is rich in $s p^{2}$ bonds. In a-C:H, the $s p^{3}$ bonds are contributed by $\mathrm{C}-\mathrm{H}$ $s p^{3}$ hybridization along with the C-C $s p^{3}$ hybridization [13].

\subsubsection{Forms of Amorphous Carbon}

Possible forms of a-C are represented by the ternary phase diagram of a-C growth in Fig. $15[13,60]$. The bottom right corner on this diagram defines the region where no C-C atomic bonds exist and therefore, no film formation is possible. Adjacent to that is the region of hydrocarbons. The bottom left corner is the region of $s p^{2}$ rich carbon, examples of which are glassy carbon and pure graphite. Navigating along the left hand side, results in the bond fraction tailoring from $s p^{2}$ to $s p^{3}$. With films containing ideally no hydrogen, an increase in the $s p^{3}$ bond fraction (about 50\% or more) leads to the regime of diamondlike carbon (DLC). With further increase in the $s p^{3}$ bonds (about $75 \%$ or more), the films are referred to as tetrahedral a-C (ta-C). It is also possible to reach to the middle of the triangle if the a-C films contain high amount of hydrogen and at the same time, exhibit a very high density. This regime is called ta-C:H [13]. 


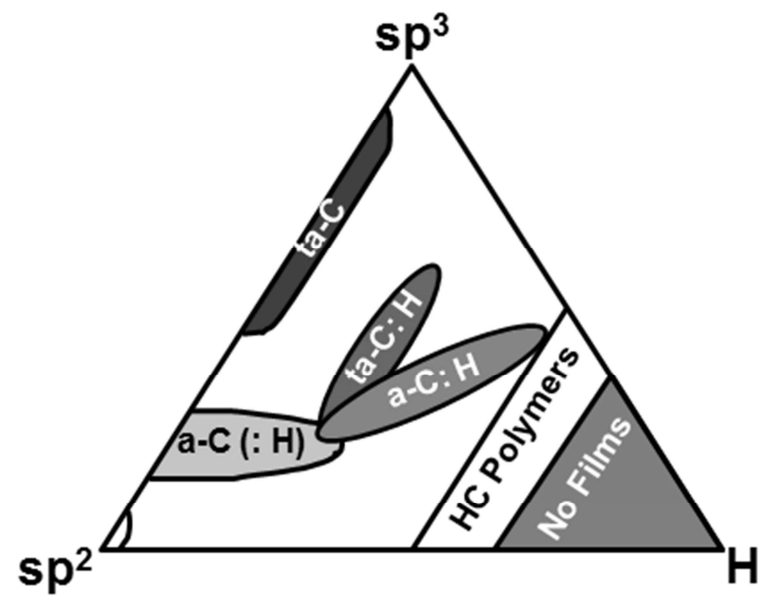

Figure 15. Ternary phase diagram for a-C growth. (After J. Robertson [13].)

\subsubsection{The Densification Model}

The $s p^{3} / s p^{2}$ bond ratio is vital for the functionality of a-C. The $s p^{3} / s p^{2}$ bond ratio can be tailored by controlling the flux and energy of the depositing species. For the a-C growth, the dependence of energy and flux of the depositing species is described by the densification model [13] which is illustrated in Figure 16.

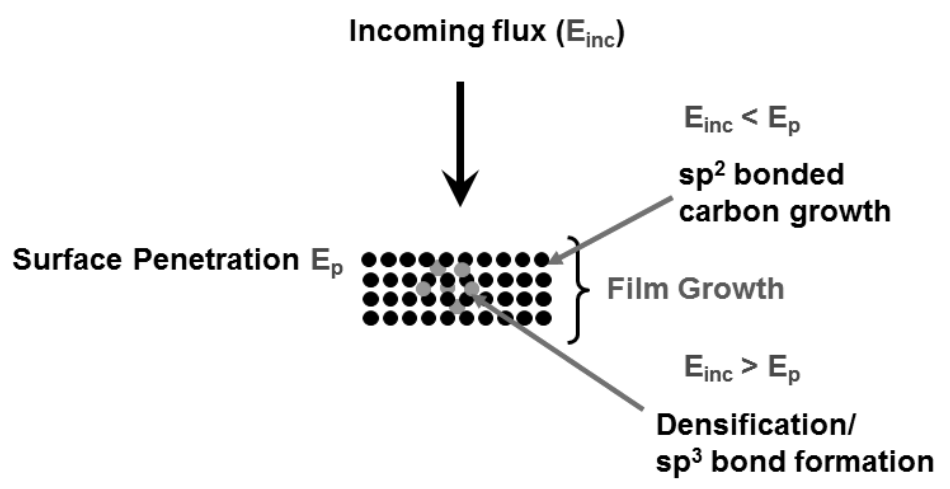

Figure 16. An schematic showing the densification model for the growth of a-C.

(After J. Robertson [5].) 
The densification model can be described as follows: Consider that the depositing species possess a certain energy $E_{i n c}$ and the atoms at the surface of the growing film are bonded with an energy $E_{b}$. Associated with these surface atoms, there is an energy which is termed as displacement energy, $E_{d}$, which is the energy required to displace an atom and form a vacancy-interstitial pair. The surface penetration threshold, $E_{p}$, is the combination of $E_{d}$ and $E_{b}$, such that [13,61],

$$
E_{p}=E_{d}+\left(-E_{b}\right) .
$$

If $E_{\text {inc }}$ is lower than $E_{p}$, the incoming atoms reside on the surface in lower energy configuration, resulting in the outward growing $s p^{2}$ layers. If $E_{i n c}$ is greater than $E_{p}$, the incoming atoms penetrate through the surface and shallow implantation (also referred to as subplantation) occurs. This results in the increase in the vacancy-interstitial pairs thereby causing an increase in the local density in the subsurface region. Since the material is amorphous therefore, the incident atoms and the implanted atoms are the same; a bond rearrangement from $s p^{2}$ to $s p^{3}$ occurs, which gives rise to an increase in the density of the films.

The process of implantation can occur in different ways. This depends on the energy of the incoming species. If $E_{\text {inc }}$ is slightly higher than $E_{p}$, the direct penetration occurs. At moderately higher incident energies as compared to $E_{p}$, the implantation occurs through the process of knock-on. At very high energies, thermal spike is caused. In the case of upper limit of energy for the knock-on process and in the region of thermal spike, there is an excess energy than what is required for the implantation. This excess energy appears in the form of heat (phonon) which causes a bond relaxation from $s p^{3}$ to $s p^{2}$ and as a consequence, the density of the film decreases to the initial level (before the implantation occurs). The $E_{p}$ for carbon is about $35 \mathrm{eV}$ while the optimum energy for the implantation is found to be about $100 \mathrm{eV}$. Typical energy range of interest is between $10-1000 \mathrm{eV}$. With this energy range, initially a transition from $s p^{2}$ dominated growth to $s p^{3}$ dominated growth occurs, and after the optimum is reached, the relaxation occurs. Fig. 17 shows the experimental verification of the densification model including the processes of densification and relaxation [62]. 


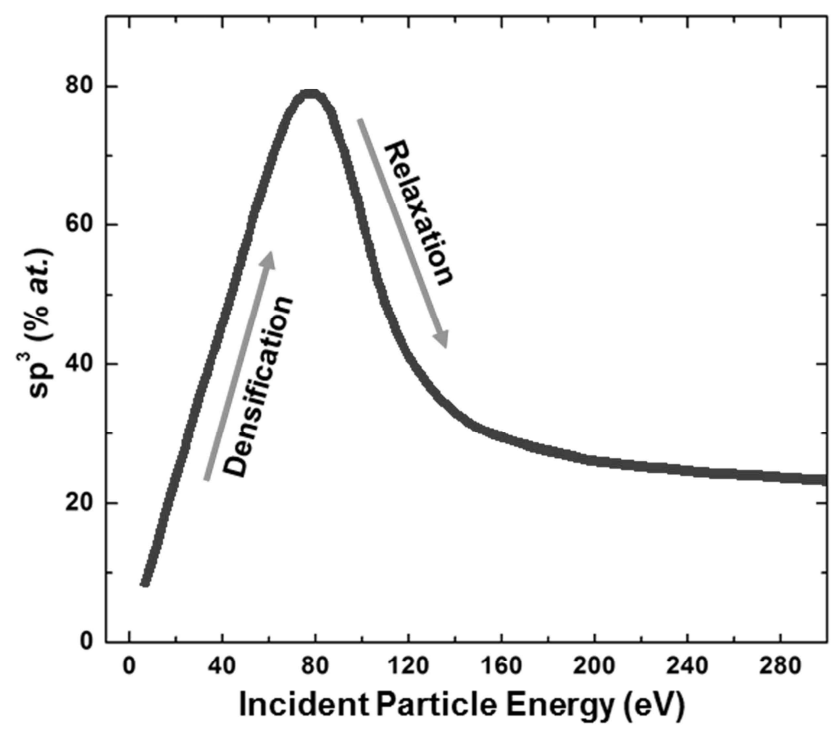

Figure 17. An experimental verification of the densification model of a-C growth showing the dependence of the densification and relaxation on the energy of the depositing ions (After [62]).

From the discussion of the densification model, it can be understood that the growth of denser and $s p^{3}$ rich a-C requires an energetic depositing flux. It is also important that the energy of the depositing flux can be controlled. This will be much easier if a large fraction of the depositing flux is ionized. Highly ionized depositing fluxes are provided by high plasma density based methods. Therefore, it is instructive to discuss the role of the high plasma density discharge processes for a-C film growth.

\subsubsection{State-of-the art of amorphous carbon}

The state of the art approaches for the growth of denser and $s p^{3}$ rich a-C include filtered cathodic vacuum arc (FCVA) and pulsed laser deposition (PLD). FCVA has been extensively employed for the synthesis of high density and $s p^{3}$ rich a-C [63]. In such a case, $\mathrm{C}$ ion energies of about $20-30 \mathrm{eV}$ in DC arc discharges while a wider energy range of $20-140 \mathrm{eV}$ in pulsed arc discharges have been reported [5,63,64]. The energetic 
depositing flux of $\mathrm{C}$ has been shown to provide a-C films with mass density reaching up to $3.2 \mathrm{gcm}^{-3}, s p^{3}$ fraction of about $88 \%$ and the hardness of about $90 \mathrm{GPa}$ [65-67]. The grown a-C film properties from FCVA are promising however, it exhibits some drawbacks. The most critical issue with this technique is the macroparticle co-deposition which makes it difficult to produce defect-free coatings. Different approaches are employed for filteration of the macroparticles however, $100 \%$ macroparticle filtration cannot be achieved. This limits its implementation for the production of high quality and cost-effective a-C coatings.

In the case of PLD, the energies of the evaporated material and the plasma density in the plume meet the energetic deposition conditions [68], which are required for the synthesis of $s p^{3}$ rich a-C. The densities of a-C grown with PLD as high as about $3 \mathrm{gcm}^{-3}$, with hardness of the films reaching $100 \mathrm{GPa}$ have been reported $[25,68,69]$ and therefore, the technique is regarded as a viable method for the synthesis of DLC and ta-C . However, there are drawbacks that are inherent to the method such as, source material cluster evaporation, lower deposition rate, costly setup, lack of lateral uniformity of the grown films as well as difficulty in making large area depositions [69]. These constraints limit the up-scaling of the technique and hence the irrelevance to the industrial setup results.

Recently, the potential of HiPIMS has been explored for the synthesis of a-C films $[15,16]$. While HiPIMS has demonstrated its capability to generate highly ionized fluxes for commonly used metals (for example $\mathrm{Ti}^{+} / \mathrm{Ti}^{0}$ upto $90 \%$ has been reported) [40], for $\mathrm{C}$ the ionized fraction is still comparatively quite low (close to 5\%) [16]. The grown a-C films have been found to exhibit mass densities of the order of $2.2 \mathrm{gcm}^{-3}$ and $s p^{3}$ bond fraction of about $45 \%$ [15]. The mass densities and sp3 fractions achieved using HiPIMS are therefore substantially lower than those achieved using FCVA and PLD $[63,68]$. In paper I, a new strategy is introduced that can facilitate an increase in the ionization of $\mathrm{C}$ in a HiPIMS discharge. The feasibility of the strategy for the synthesis of high density aC films is also investigated. 


\subsection{Metal-Oxide Thin Films}

\subsubsection{Ti-0}

$\mathrm{TiO}_{2}$ thin films are used as optical coatings in various applications such as photocatalytic and photoelectrochemical applications [70-73]. The three different phases that $\mathrm{TiO}_{2}$ is found in are anatase, rutile and brookite. The crystalline structure of anatase and rutile is tetragonal whereas that of brookite is orthorhombic [74]. Room temperature synthesis of $\mathrm{TiO}_{2}$ thin films using magnetron sputtering results in x-ray amorphous structures and elevated growth temperatures are required to obtain crystalline phases. Crystalline anatase phase has been shown to be formed at about $200{ }^{\circ} \mathrm{C}$ [75] whereas higher temperatures $\left(>600{ }^{\circ} \mathrm{C}\right)[70]$ are required to form crystalline rutile phase. Energetic deposition conditions that are achieved in reactive HiPIMS process have been shown to facilitate room temperature synthesis of $\mathrm{TiO}_{2}$ thin films exhibiting anatase and rutile phases [22]. In paper VI, the study is further extended by analyzing the effect of peak power in a reactive HiPIMS discharge on the phase formation of $\mathrm{TiO}_{2}$ thin films.

\subsubsection{Al-O}

$\mathrm{Al}_{2} \mathrm{O}_{3}$ is a ceramic material which exhibits superior mechanical and optical properties and hence is a suitable candidate for applications that require oxidation resistant, chemically inert, hard and optically transparent coatings [21,76-78]. Among the various phases of Al-O system $\left(\alpha, \kappa, \theta, \eta\right.$ and $\gamma$ ), the single thermodynamically stable phase is $\alpha-\mathrm{Al}_{2} \mathrm{O}_{3}$. Room temperature synthesis of $\mathrm{Al}_{2} \mathrm{O}_{3}$ using sputter deposition results in amorphous thin films. Elevated temperatures $\left(180-700{ }^{\circ} \mathrm{C}\right)$ can facilitate the synthesis of metastable phases $\left(\kappa-, \theta-\right.$ and $\gamma-\mathrm{Al}_{2} \mathrm{O}_{3}$ ) whereas thermodynamically stable $\alpha-\mathrm{Al}_{2} \mathrm{O}_{3}$ can be synthesized at $>750^{\circ} \mathrm{C}$ [78]. Energetic ion bombardment during the sputter deposition and plasma assisted CVD has shown to facilitate low temperature $\left(650{ }^{\circ} \mathrm{C}\right)$ synthesis of $\mathrm{Al}_{2} \mathrm{O}_{3}[21,79,80]$. In paper $\mathbf{V}$, the properties of an Al-O HiPIMS discharge are investigated where the effect of plasma chemistry, plasma energetics and ion composition is studied on the discharge current behavior of Al-O in comparison to Ti-O. In paper VI, $\mathrm{Al}-\mathrm{O}$ thin films are grown to serve as a reference for comparison of film properties of AlSi-O thin films (see next section). The discharge characteristics studied in paper $\mathrm{V}$ are 
again used in paper VI for a reference on plasma properties when plasma properties of Al-Si-O discharges are investigated.

\subsubsection{Al-Si-O}

$\mathrm{Al}-\mathrm{Si}$ is a binary eutectic alloy with its eutectic temperature and composition being 577 ${ }^{\circ} \mathrm{C}$ and 12.6 at.\% Si respectively $[81,82]$. Examples of ceramics based on Al-Si are Sialons $(\mathrm{Si}-\mathrm{Al}-\mathrm{O}-\mathrm{N})$ and mullite $\left(3 \mathrm{Al}_{2} \mathrm{O}_{3} \cdot 2 \mathrm{SiO}_{2}\right)$ [83-85] which have been used in high temperature, electronic and optical applications $[83,85]$. Al-Si-O thin films offer unique possibilities as optical coatings by combining low refractive index of $\mathrm{SiO}_{2}$ and high abrasion resistance of $\mathrm{Al}_{2} \mathrm{O}_{3}$. This is a promising pathway for designing antireflective coatings where optical transparency (refractive index< 1.6 ) $[86,87]$ together with abrasion resistance and mechanical strength (hardness $>20 \mathrm{GPa}$ ) is highly desired. The mechanical strength and optical transparency of both $\mathrm{Al}_{2} \mathrm{O}_{3}$ and $\mathrm{SiO}_{2}$ are affected by their structure [88]. Room temperature synthesis of $\mathrm{Al}_{2} \mathrm{O}_{3}$ and $\mathrm{SiO}_{2}$ results in amorphous structures [88]. Amorphous phases of $\mathrm{Al}_{2} \mathrm{O}_{3}$ and $\mathrm{SiO}_{2}$ exhibit low refractive indices $(\sim 1.6$ and 1.45 respectively) but the mechanical properties (hardness $\sim 10 \mathrm{GPa}$ ) are not suitable for strong abrasive behavior. Employing energetic ion bombardment and elevated growth temperatures is a step forward to the formation of crystalline phases with desired properties. In this thesis, the synthesis of $\mathrm{Al}-\mathrm{Si}-\mathrm{O}$ thin films for obtaining good mechanical and optical properties that are suitable for antireflective behavior using HiPIMS is performed. The plasma properties and discharge current behavior for Al-Si-O discharges are also investigated. A correlation between the plasma and film properties is sought. The results are compiled in paper VI. 


\section{Chapter 5}

\section{Plasma and Thin Film Characterization}

In this thesis, various methods for the investigation of plasma and film properties have been employed. In the subsequent section, in no way comprehensive, an introduction with experimental details of these methods is provided.

\subsection{Plasma Characterization}

The plasma characterization in this thesis, involved the determination of the plasma parameters (such as $n_{e}$ and $T_{e}$ ) and the measurement of ion energy distribution functions (IEDF) of ionized species in the plasma discharges. The plasma parameters were determined by Langmuir probe measurements while the IEDFs were measured by mass spectrometry. A detailed description of the two methods is presented in the following sections.

\subsubsection{Langmuir Probe Measurements}

The idea behind the Langmuir probe measurements is to collect current-voltage $(I-V)$ characteristic of a plasma discharge using a probe (typically a cylindrical metal wire) to characterize the plasma. The method provides a possibility of determining important plasma parameters such as $n_{e}$ and $T_{e}$ by determining the electron energy distribution function (EEDF). The concept of plasma diagnosis by means of measuring the $I-V$ characteristic using such a probe was introduced by Irving Langmuir in 1926 [24]. These probes are therefore called Langmuir probes.

In principle, any electrode immersed into a plasma which can draw ion and electron currents such as by applying external bias potential, can serve the purpose. The dimensions and the choice of the material of the probe are important since the probe is 
immersed into the plasma where it may subject to drawing large currents. Therefore, a high melting point material is chosen for the probe. The dimensions of the probe are chosen such that it may not affect the ionization and energy balance and discharge current distribution in the surrounding plasma [89]. In this work, a cylindrical wire made of tungsten encapsulated in a ceramic insulating tube is used as a probe (the details will follow later in the section). The dimension of the probe is chosen according to the criteria $[89,90]$ that the length of the probe should be greater than the radius of the probe tip as well as the radius of the insulating tube (to avoid shadowing effects) and these two radii should be greater than the Debye length (see equation (3.1) in chapter 3 for the Debye length).

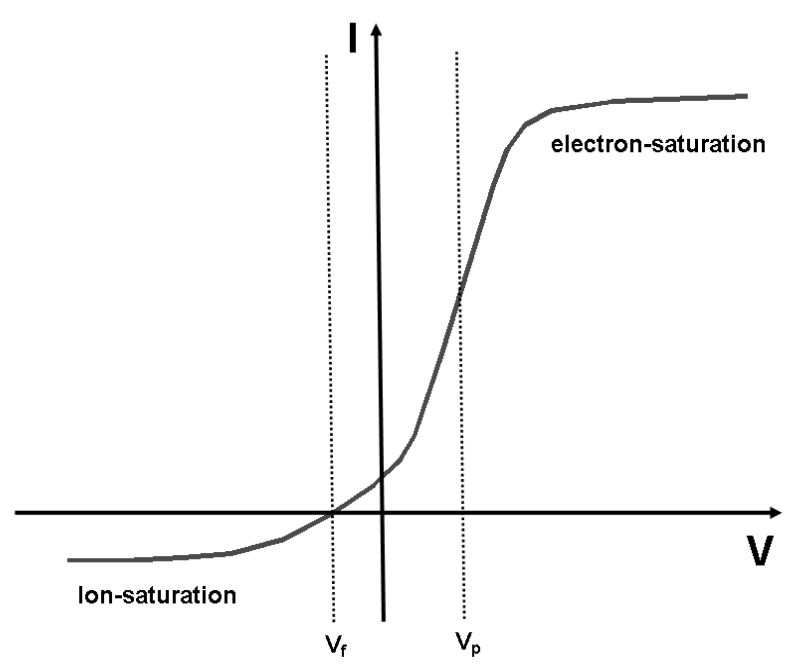

Figure 18. A typical $I-V$ characteristic of a plasma discharge, obtained from Langmuir probe measurement (After Lieberman [24]).

A typical $I-V$ characteristic of a plasma discharge is shown in Fig. 18. $V_{f}$ is the floating potential, which is the potential at which the ion and electron currents are equal and at this potential, a probe placed in the plasma does not draw any current. $V_{p}$ is the plasma potential which is the potential of the plasma with respect to the grounded chamber walls. 
Usually, the plasma is at a positive potential (a couple of volts) with respect to the chamber walls which stems from a faster diffusion of the electrons through the chamber walls as compared to the heavier ions, leaving the plasma at a positive potential. The bias voltage (here denoted as $V_{b}$ ) can be regarded as positive or negative with respect to $V_{p}$. At $V_{b}=V_{p}$, the main contribution to the current is from electrons. For $V_{b}>V_{p}$, the probe is positive with respect to the plasma and the electron collection further increases reaching to the region of electron saturation. For $V_{b}<V_{p}$, the probe is negative with respect to the plasma and ion collection increases until $V_{b}$ reaches to $V_{f}$. At this value, the probe does not draw any current $\left(I_{\text {electron }}=I_{\text {ion }}\right)$. Decreasing $V_{b}$ further, leads to the region of ion saturation. The ion saturation current is substantially lower than the electron saturation due to the much greater ion mass.

From the $I-V$ characteristic of the plasma, EEDF is obtained using the Druyvesteyn formula [24],

$$
g_{e}(V)=\frac{2 m}{e^{2} A_{p r}}\left(\frac{2 e V}{m}\right)^{\frac{1}{2}} \frac{d^{2} I_{e}}{d V^{2}},
$$

where $A_{p r}$ is the probe area, $m$ and $e$ are the electron mass and charge, $I_{e}$ is the electron current, and $V=V_{p}-V_{B}$ is the probe potential with respect to the plasma potential. Once the EEDF is known, the electron density is found by,

$$
n_{e}=\int_{0}^{\infty} g_{e}(E) d E
$$

In low-pressure, weakly-ionized discharges, the EEDF is generally non-Maxwellian (often bi-Maxwellian) and the electron temperature is considered as an effective electron temperature, $T_{\text {eff }}$, representing the mean electron energy $\langle E\rangle$ determined from the EEDF. The average electron energy is, 


$$
\langle E\rangle=1 / n_{e} \int_{0}^{\infty} E g_{e}(E) d E,
$$

and the effective electron temperature is defined as,

$$
T_{\text {eff }}=2 / 3\langle E\rangle .
$$

For the Langmuir probe measurements performed in this work, a cylindrical shaped Langmuir probe made of a thin tungsten wire having a length of $5 \mathrm{~mm}$ and a diameter of $125 \mu \mathrm{m}$ was used. The probe was encapsulated into a ceramic insulating tube. The tip of the probe was immersed into plasma while the rear end of the probe was connected to the external circuitry for applying the bias voltage and measuring the resulting current drawn by the probe from the plasma body. For the Langmuir probe measurements performed in the work presented in paper I and III the probe was placed at the axis of the magnetron at a separation of $6 \mathrm{~cm}$ from the target surface. In both of the cases, the probe was lengthwise parallel to the target surface. The probe was biased with the help of a probe bias power supply. The bias voltage was varied with the help of a potential divider and the resulting probe current was measured as a voltage drop across a $1.1 \mathrm{Ohm}$ shunt resistance. An analog-to-digital converter (PICO ADC 212 oscilloscope, 12-bit resolution module), triggered by the cathode pulse, was used in order to convert the analog form of the current/voltage into digital form to feed it to the computer. The data acquisition was performed by a lab-view program.

The probe bias voltage $V_{b}$ was varied in steps of 0.02 volts, ranging from -40 Volts to +20 Volts, to collect the ion and electron currents. The measurements were made timeresolved for the case of HiPIMS, in order to take the temporal behavior of the discharge current into account. At each voltage step, the current was recorded in 500 equal time intervals, each having a width of 320 ns. This means that the current was recorded for $160 \mu \mathrm{s}$ after the initiation of the pulse. In this way, the $I-V$ curve for each time value can be reconstructed and analyzed. Smoothing and filtering of the acquired data was performed for the purpose of noise suppression. This is necessary since the plasma itself 
is inherently noisy. Also, the EEDF is determined by using the second derivative of the $I$ - $V$ curve (see Eq. 5.1) therefore, any noise present in the data can be greatly amplified during the differentiation. The noise suppression was performed by digital smoothing of the measured $I-V$ characteristic curve by taking an average of 30 samples followed by Blackman window filtration. The details of how the digital smoothing and filtering works, can be found elsewhere [45].

\subsubsection{Mass Spectrometry}

The energy distribution functions of the ionized species in the plasma discharges were measured using a mass spectrometer. The mass spectrometer used, is capable of performing mass-selected, energy-resolved measurements in both, the time-averaged as well as in time-resolved modes. The plasma species with energies up to $100 \mathrm{eV}$ with a resolution of $0.05 \mathrm{eV}$ and masses up to $500 \mathrm{amu}$ with a resolution of $0.01 \mathrm{amu}$ can be recorded. The details of how the instrument performs a measurement, is briefly described as follows:

The mass spectrometer consists of electrostatic lenses, energy and mass filters and a detector, as shown in Fig. 19. The operation of the spectrometer can be divided into four major sections which include, an extractor probe, energy filter, mass filter and a detector. The extractor probe includes a front end with an orifice, which is simply a circular entrance slit, of diameter between $50 \mu \mathrm{m}$ to $300 \mu \mathrm{m}$, and an ionization source which is a filament which when heated through current, releases electrons. The ionization source is used when neutral species are analyzed such as during residual gas analysis (RGA). For the measurements of energy distribution functions of ions, the ionization source is turned off. 


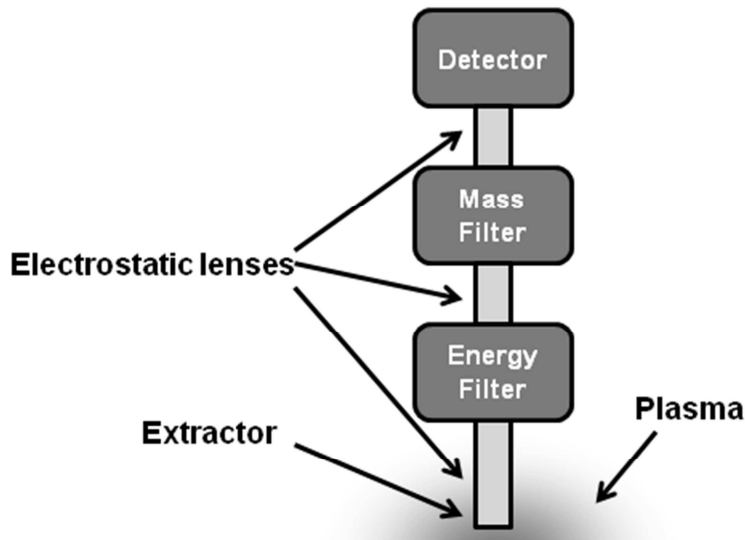

Figure 19. An schematic showing the main sections of a mass spectrometer.

The extractor probe is immersed into the plasma body with its front end biased, grounded or kept at a floating potential. The ions from the plasma are accelerated to the entrance slit with a potential difference, which is the difference between the plasma potential and the potential at the front end. The ions are then extracted and are focused to the entrance of the energy filter using an electrostatic lens in the extractor section. The energy filter is a so-called Bessel box [91,92] which filters out the ions according to the selected energy. Ions of certain energy exit from the Bessel box which are again focused using an electrostatic lens to the mass filter. The mass filter is a quadruple mass filter which then filters out the ions of undesired mass and sends the species of the selected mass to the detector. The detector is the secondary electron multiplier (SEM) detector. The details of the Bessel box and the quadruple mass filter can be found elsewhere [91,92].

Fig. 20 is an example of measured IEDFs measured in paper VI for $\mathrm{O}^{1+}$ ions in a Ti-O HiPIMS discharge. The IEDFS were measured by recording time-averaged, energyresolved spectra. The data was recorded for $100 \mathrm{~ms}$ using an energy range of $100 \mathrm{eV}$ and the step size of $0.05 \mathrm{eV}$. In the similar manner, the ionized fluxes for C-HiPIMS and Al- 
$\mathrm{Si}-\mathrm{O}$ as well as $\mathrm{Al}-\mathrm{O}$ and Ti-O based HiPIMS discharges were also measured in paper I, paper IV and paper $\mathrm{V}$.

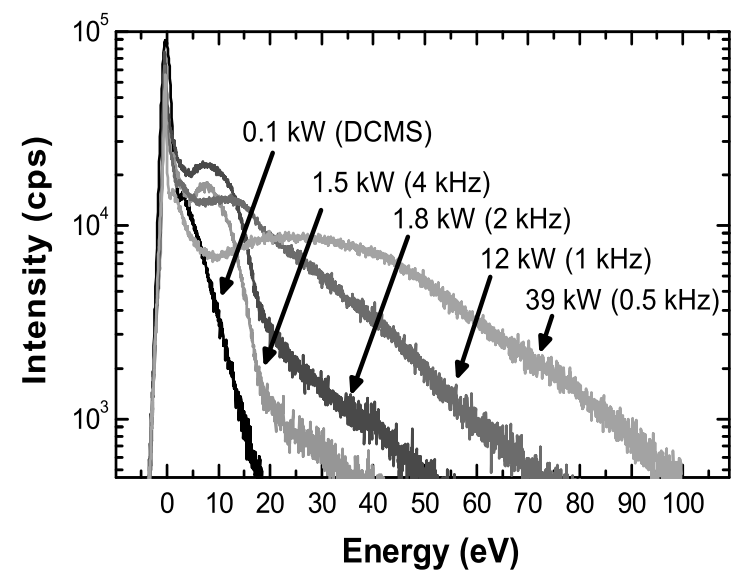

Figure 20. The $\mathrm{C}^{1+}$ IEDF measured for the case of $83 \%$ Ne discharge.

\subsection{Thin Film Characterization}

Various thin film characterization techniques have been used in this thesis for investigating the structural, chemical, mechanical and optical properties of the films. The details of these techniques are described in the following sections.

\subsubsection{X-ray Diffractometry}

Diffraction of $\mathrm{x}$-rays from three dimensional periodic crystal lattice of a material is an invaluable tool to probe the material properties including but not limited to, crystal structure, its preferred orientation, grain size. Typically the energy of the x-rays used in $\mathrm{x}$-ray diffractometry (XRD) is of the order of few $\mathrm{keV}$ which corresponds to the wavelengths of $\mathrm{x}$-rays that are of the order of the atomic spacing in the material - a requirement to fulfill the condition of diffraction [93]. By measuring the diffracted intensities scanned over a range of diffracted angles, x-ray diffractograms are constructed. The information about material properties is gained from peak intensity, peak position, peak width, a shift in the peak from the expected value etc. 


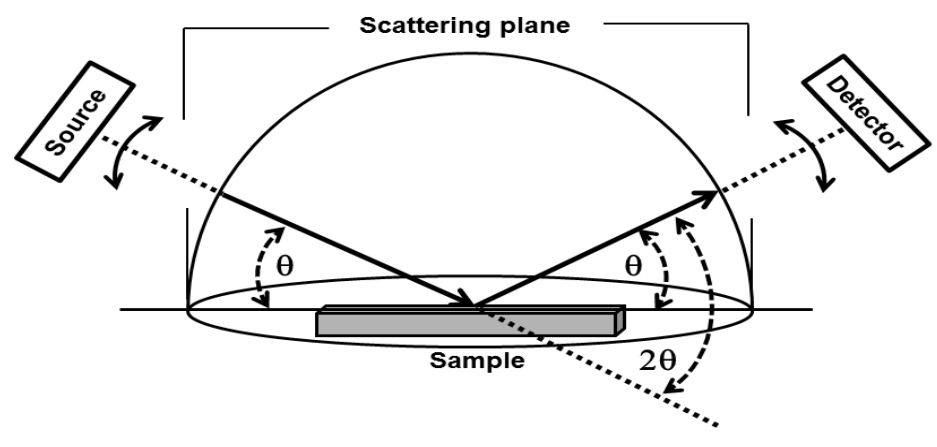

Figure 21. Schematic showing the principle of $x$-ray diffraction in BraggBrentano configuration (Adapted from [93]).

Diffractograms are typically constructed by using the measurement setup in the so-called symmetric $\theta-2 \theta$ configuration where $\theta$ is the angle of incidence of the $\mathrm{x}$-rays measured with respect to the surface of the sample and $2 \theta$ is the diffracted angle. In this configuration, the source of the x-rays and the detector are scanned synchronously such that the incidence angle and the diffracted angle remain the same throughout the scanning. In such a configuration, only those crystal planes are probed that are parallel to the sample surface.

Often during the x-ray diffractometry of thin films, the diffractograms are dominated by the $\mathrm{x}$-rays diffracted from lattice planes of the substrate which is mainly due to the small thickness of the films (in the order of $\mathrm{nm}$ ) and comparatively large penetration depths of $\mathrm{x}$-rays (of the order of $\mu \mathrm{m}$ ). This is particularly relevant when highly ordered substrates such as Si are used for thin film deposition. In order to circumvent this issue, the method of grazing incidence $\mathrm{x}$-ray diffraction (GIXRD) is used where the x-rays enter the specimen at very small fixed angles (few degrees) thereby increasing the path travelled by the x-rays significantly. Since the incidence angle is fixed, the diffractograms are 
obtained by varying the diffraction angle thereby also probing the planar orientation which is not parallel to the sample surface.

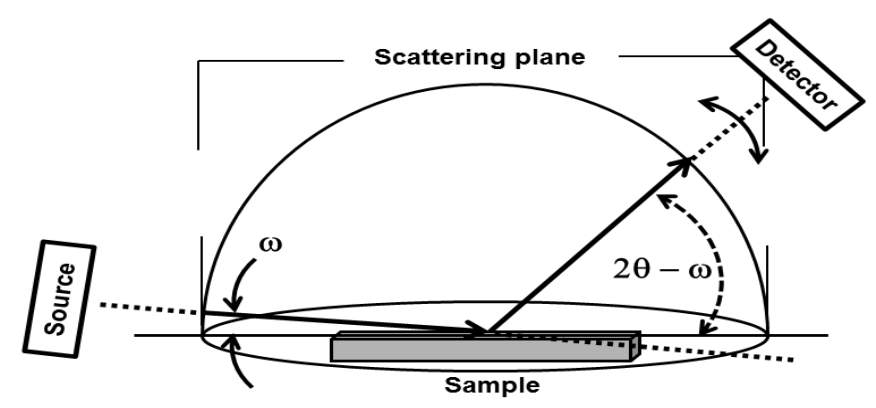

Figure 22. Schematic showing the principle of grazing incidence x-ray diffraction (Adapted from [93]).

In paper IV, the phase contents of $\mathrm{TiO}_{2}$ thin films were analyzed by GIXRD by using a Philips X'Pert-MRD diffractometer with de-coupled sample $(\omega)$ and detector $(2 \theta)$ axes in diffraction geometry. The diffractometer was equipped with a copper $\mathrm{x}$-ray source $(\mathrm{Cu}$, $\mathrm{K}_{\alpha} \lambda=1.54 \AA$ ) operated with $45 \mathrm{kV}$ and $40 \mathrm{~mA}$. The incident angle was kept fixed at $3^{\circ}$ while the diffractograms were obtained by scanning the detector over the range of 20 $65^{\circ}$. The grazing incidence x-ray diffractograms is shown in Fig. 23. 


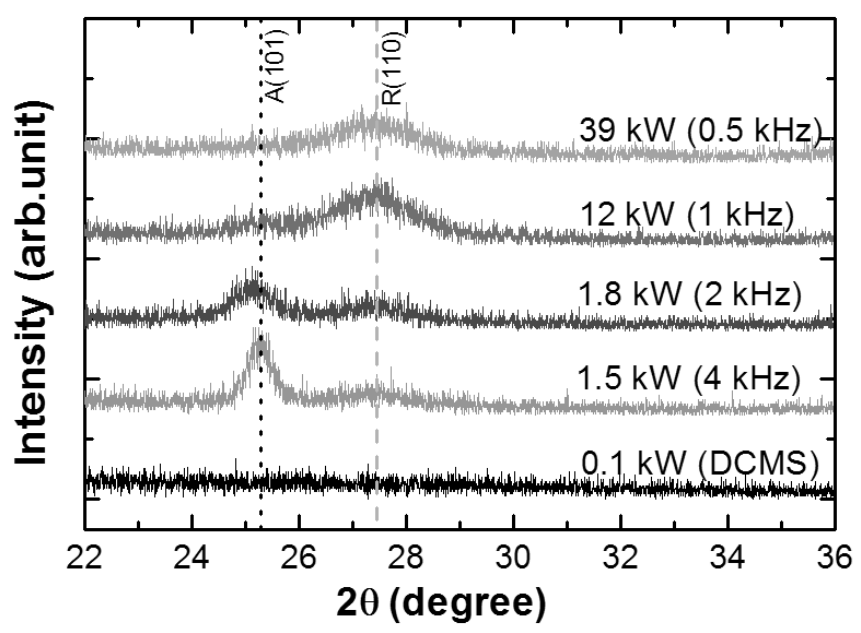

Figure 23. GIXRD of $\mathrm{TiO}_{2}$ thin films grown using HiPIMS (paper VI).

\subsubsection{X-ray Reflectometry}

$\mathrm{X}$-ray reflectometry (XRR) is widely employed for the determination of mass density, surface roughness and film thickness. The method employs monochromatic x-rays to generate a characteristic pattern of a sample - which is an interference pattern, resulting due to the total external reflection of x-rays [93].

Since the refractive index of x-rays is slightly less than unity, the total external reflection occurs at very small incidence angles. Due to this reason, grazing incidence angles are used and often, the method is also referred to as grazing incidence x-ray reflectometry. When the incidence angle increases above the critical angle (the angle at which total external reflection occurs), the x-rays start to penetrate into the film. The specular reflections from the air-film and from the film-substrate interfaces interfere to give the characteristic pattern. The critical angle, $\theta_{c}$, for this case can be derived by using Snell's law at the air-film interface, which is expressed as [93,94],

$$
\theta^{2}{ }_{c}=\frac{r_{0} \lambda^{2} Z N_{A} \rho_{m}}{\pi A}
$$


Here, $r_{0}$ is the classical electron radius, $\lambda$ is the wavelength of x-ray radiation, $Z$ and $A$ are the charge number and mass number of the material, $N_{A}$ is the Avagadro's number and $\rho_{m}$ is the mass density of the material. By determining $\theta_{c}$, the $\rho_{m}$ of the sample can be determined using Eq. 5.5. It is also common to perform a curve fitting using a simulated XRR curve which enables one to determine the film thickness, surface roughness as well as mass density of the films.

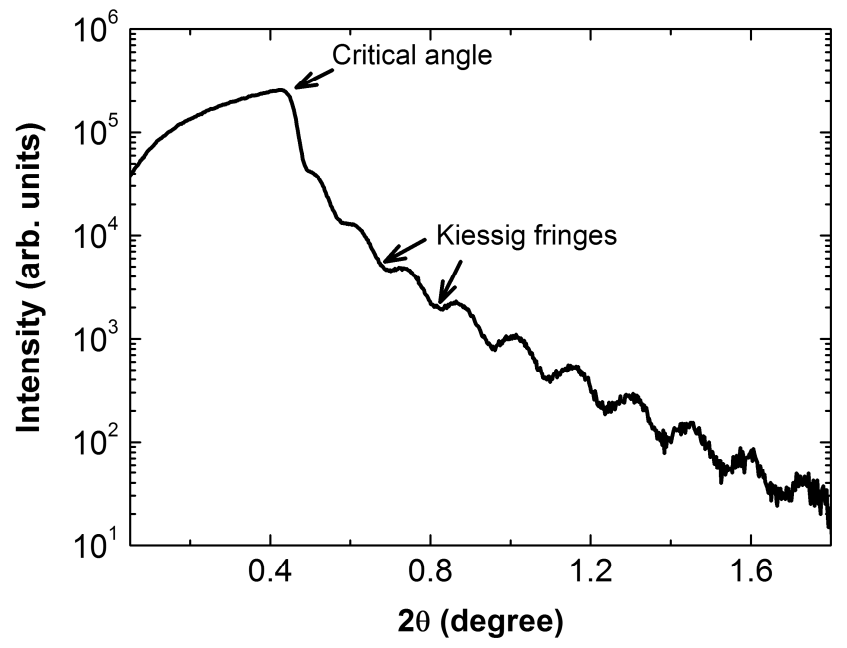

Figure 24. A characteristic XRR curve of an a-C film grown using a Ne-based HiPIMS discharge at a substrate bias potential of -100 V (paper I).

For the work presented in paper I, II and III, the XRR measurements were performed by using a Philips X'Pert-MRD diffractometer with de-coupled sample $(\omega)$ and detector (20) axes in reflection geometry. The diffractometer was equipped with a copper $\mathrm{x}$-ray source $\left(\mathrm{Cu}, \mathrm{K}_{\alpha} \lambda=1.54 \AA\right.$ ) operated with $45 \mathrm{kV}$ and $40 \mathrm{~mA}$. An example of measured XRR curve from such a measurement is shown in Fig. 24 whereas a simulated curve that is fitted to the measured curve is shown in Fig. 25. 


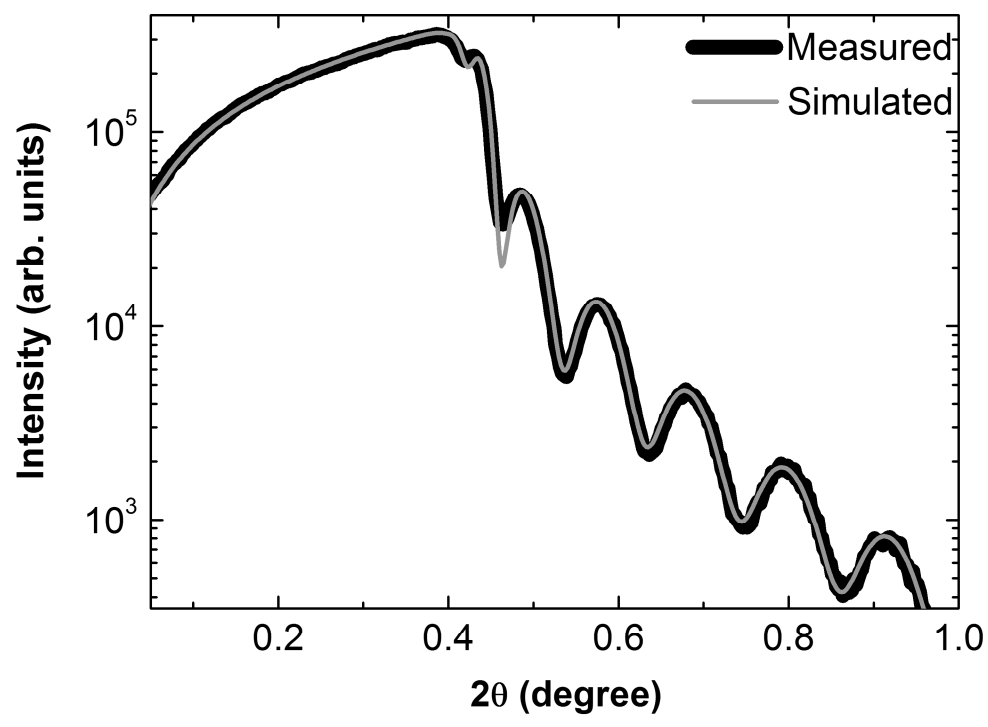

Figure 25. A simulated XRR curve fitted on a measured XRR curve that was obtained for an a-C thin film grown using Ar-based HiPIMS process at a substrate bias potential of $-V_{f l}$.

\subsubsection{Elastic Recoil Detection Analysis}

Chemical composition and elemental depth profiles of thin films can be determined by ion beam analysis. Elastic recoil detection analysis (ERDA) is one such ion beam analysis method which is based on collecting and analyzing the sample atoms that are scattered in the forward direction by an incident beam of heavy ions that possesses energy in the order of several tens of MeV [95]. From the measured energy spectrum of the scattered atoms, the depth profiles are obtained. In this work, the chemical compositions of a-C and $\mathrm{TiO}_{2}$ thin films were determined by means of time-of-flight ERDA (ToF-ERDA) setup using a $32 \mathrm{MeV}^{127} \mathrm{I}^{8+}$ beam. The incident angle of the beam with respect to the surface normal was chosen as $67.5^{\circ}$, while the detector was placed at a recoil angle of $45^{\circ}[96]$. 


\subsubsection{Raman Spectroscopy}

Raman spectroscopy is a common method for qualitative structural analysis of various forms of a-C thin films [97,98]. The method is based on measuring the changes in the energy of the incident light due to the inelastic scattering from molecular or crystal vibrations. The inelastic scattering can result from the excitation of the molecules from the ground state (Stokes scattering) in which case the energy of the incident photon is reduced by an amount equal to the molecular or crystal vibrations. The inelastic scattering can also occur if the transition starts from an excited vibrational level (antiStokes scattering) in which case the energy of the incident photon is up-shifted. In both of the cases, the scattered light provides the information about the molecular or crystal vibration modes $[98,99]$.

In Raman spectroscopic measurement, typically a laser beam with wavelength in the visible, near infra-red or near ultra-violet range is used. The inelastically scattered light from the sample is collected and the scattered intensity as a function of the shift in the wavelength with respect to the wavelength of the laser beam is plotted. Typically the Raman spectrum of a-C shows two broad peaks; the $\mathrm{G}$ (graphite) peak at about $1560 \mathrm{~cm}^{-1}$ and the $\mathrm{D}$ (disorder) peak at about $1350 \mathrm{~cm}^{-1}$ [98]. The origin of the G-peak is attributed to the $\mathrm{C}-\mathrm{C} \mathrm{sp}^{2}$ bond stretching vibrations whereas the D-peak is associated with the breathing modes of $\mathrm{sp}^{2}$ bonds in the ring structure (aromatic rings). The G-peak can therefore be observed in both aromatic rings as well as olefenic chains while the D-peak is observed when the ring structure is disrupted (disorder) which allows breathing vibrations in the remaining rings. The D-peak is therefore not observed in a perfect graphite structure where the structure consists of aromatic rings. Several Raman parameters can be used for qualitative structural analysis of a-C thin films. These include G- and D-peak positions, G-peak width, intensity or area ratio of D-to-G peak (I(D)/I(G) or $\mathrm{A}(\mathrm{D}) / \mathrm{A}(\mathrm{G}))[97,98]$. 


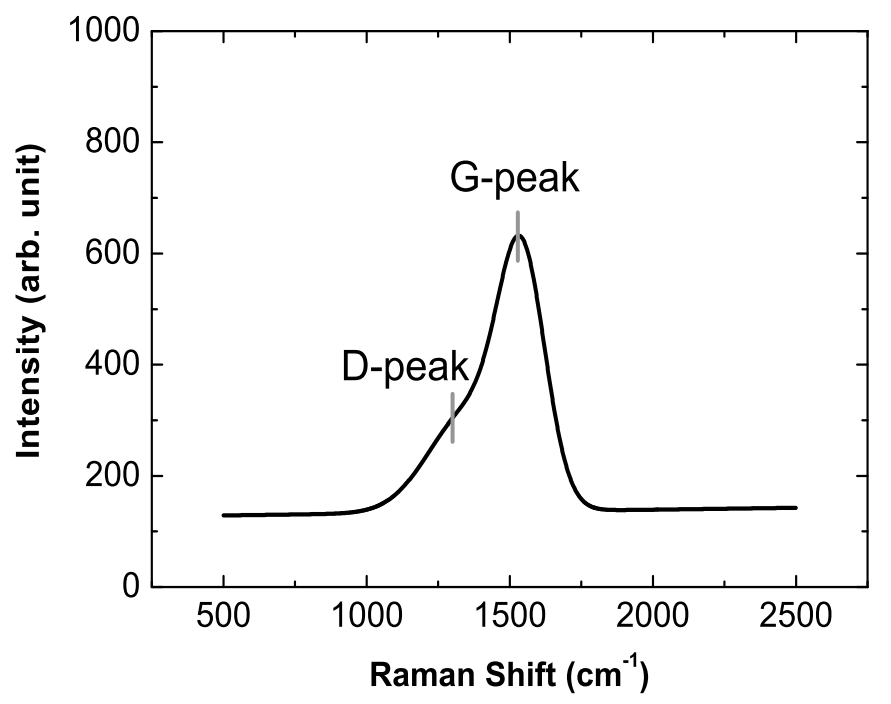

Figure 26. A Raman spectrum of an a-C:H thin film grown using $\mathrm{Ne}+\mathrm{Ar}: \mathrm{C}_{2} \mathrm{H}_{2}$ HiPIMS discharge at a substrate bias potential of $-200 \mathrm{~V}$.

In paper III, Raman spectroscopy was used for the structural analysis of a-C:H thin films. The measurements were performed with a Renishaw inVia Raman microscope equipped with an argon laser of wavelength $514.5 \mathrm{~nm}$. Care was taken to avoid sample damage from the laser exposure, which was $40 \mu \mathrm{W}$ for $15 \mathrm{~s}$. Two Gaussian peak shapes were fitted to the region $950 \mathrm{~cm}^{-1}$ to $1800 \mathrm{~cm}^{-1}$ region, and a linearly increasing background was subtracted. An example from such a measurement is shown in Fig. 26.

\subsubsection{Ex-Situ Stress Measurement}

Thin films that are in a stressed state when deposited onto a substrate cause the substrate to bend. The bending of the substrate is correlated to the elastic compliance of the substrate, the substrate thickness as well as the force per unit width that a film exerts on the substrate. The latter depends on the average stress in the film as well as on the film thickness. The relationship between all these parameters can be expressed in the form of modified Stoney equation [100,101]: 


$$
\frac{F}{w}=\sigma t_{f}=\frac{1}{6} Y_{s} t_{s}^{2} \kappa
$$

In Eq. $\frac{F}{w}$ is the force per unit width of the substrate, $\sigma$ the average stress, $t_{f}$ the thickness of the film, $Y_{s}$ the biaxial elastic modulus of the substrate, $t_{s}$ the thickness of the substrate and $\kappa$ is the curvature of the substrate.

The curvature of the substrate and hence film stress in this thesis was measured using laser-based wafer curvature method. In this method, a laser beam is split into a linear array of parallel beam using a beam splitting mirror. The beams are reflected off the substrate and their positions are recorded using a CCD camera both, before and after the film deposition. Changes in the positions of the beam spots on the substrate before and after the film deposition gives the curvature which is related to the film stress. Using the beam spot positions, the curvature can be determined as:

$$
\kappa=\frac{1}{R_{c}}=\frac{d-d_{0}}{d_{0}}\left(\frac{1}{2 L \cos \alpha}\right)
$$

where $R_{c}$ is the radius of curvature, $d-d_{0}$ the spacing between the laser beam spots, $L$ the distance between the CCD and the substrate and $\alpha$ is the incident angle of the laser beam onto the substrate.

\subsubsection{Nanoindentation}

Nanoindentation measurements are performed for analyzing the mechanical properties (hardness and elastic modulus) of thin films. The method is based on recording loaddisplacement curves while causing plastic deformation to the sample surface using an indenting object. The load-displacement curves represent the applied force vs indentation depths during loading and unloading of the indent into the sample surface. The hardness of the sample is determined from the maximum load applied whereas the elastic modulus is obtained from the characteristics of unloading curve [102].

Typically, a sharp diamond tip is employed as an indenting object. The force on the tip is chosen such that it does not penetrate into the sample to the depths where substrate 
effects become pronounced. Typically, $10 \%$ rule is applied which means that the indentation depth should not exceed $10 \%$ of the thickness of the film. However, care must be taken to avoid too shallow indentations which will also result in incorrect probing of the plastic deformation zone. In paper II and III, the hardness of a-C:H thin films were measured using a nanoindenter (UMIS-2000, Fischer-Cripps Laboratories) by employing a Berkovich shaped diamond tip. The hardness values were obtained from the indentation data using the Oliver-Pharr method.

\subsubsection{Scanning Electron Microscopy}

Scanning electron microscopy (SEM) is widely used for collecting the surface topographic information of specimen by recording images. The images in an SEM are recorded by collecting the backscattered electrons and secondary electrons, which are emitted from the specimen in response to an incident electron beam [1] — which can be accelerated to the voltages up to $20 \mathrm{kV}$. For the work presented in paper II, III and IV, the cross-sectional images thin films were obtained by a LEO 1550 Gemini SEM setup using an inLens detector. An acceleration voltage of $5 \mathrm{kV}$ and magnifications of $35 \mathrm{k}$ and $50 \mathrm{k}$ were used.

\subsubsection{Sepctroscopic Ellipsometry}

Spectroscopic ellipsometry is widely employed for investigating the optical as well as electrical properties of materials. In this method, a wide band light spanning over the spectral range of IR to UV is typically used. For investigating the properties of a specimen, the light beam is polarized, made incident on the sample which upon reflection undergoes a change in its polarization again. The changes in the reflected beam with respect to its amplitude and phase are recorded which are used to extract information about the specimen. In this thesis, the ellipsometric measurements have been performed for obtaining the optical properties of Al-Si-O (paper V) and Ti-O (paper VI). 


\section{Chapter 6}

\section{Summary and contribution to the field}

In this section, I will summarize the results from the appended papers. Papers I-III deal with the synthesis of a-C thin films where both $\mathrm{H}$-free and hydrogenated forms of a-C were synthesized using HiPIMS-based deposition processes. In paper IV, fundamental aspects of reactive HiPIMS discharges based on commonly used metal-oxide systems (Ti-O and Al-O) were studied. The knowledge acquired in this study was utilized to gain an insight into the discharge characteristics of a ternary metal-oxide (Al-Si-O) system, which comprises paper V. Paper VI is based on the investigations on the phase composition of Ti-O thin films with respect to the HiPIMS peak power.

\section{Paper I}

Amorphous carbon thin film growth using magnetron sputtering encounters several issues. One of the main issues with conventional magnetron sputtering (DCMS, RFMS) is its inability to facilitate the synthesis of high density phases of a-C such as DLC and taC. This is mainly due to lack of ionized $\mathrm{C}$ fluxes which is a consequence of low plasma densities achieved and high ionization cross-section of C. HiPIMS discharges when operated using Ar as a buffer gas generate higher plasma densities as compared to DCMS and RFMS therefore an increased $\mathrm{C}^{+} / \mathrm{C}^{0}$ ratio is obtained. However, the ionized fraction of $\mathrm{C}$ is still low $(\sim 5 \%)$. In this paper, we presented a strategy to increase the $\mathrm{C}$ ionization by electron temperature enhancement in a HiPIMS discharge. This was achieved by using a higher ionization potential buffer gas (Ne) instead of Ar. By measuring the electron temperature, $T_{e}$ and electron density, $n_{e}$ and calculating the mean ionization length, $\lambda_{\text {miz }}$ of the sputtered $\mathrm{C}$, it was found that the Ne-HiPIMS discharge provided a higher $T_{e}$ and lower $\lambda_{\text {miz }}$ as compared to Ar-HiPIMS discharge. This suggested an increased C ionization and in order to investigate this further, $\mathrm{C}^{+}$ion fluxes at the substrate position 
were measured. It was found that an energetic $\mathrm{C}^{+}$ion population with larger flux is obtained in the case of Ne-HiPIMS discharge. A direct consequence of the increased $\mathrm{C}$ ionization was observed in the resulting a-C film properties where a-C films with mass densities in the order of $2.8 \mathrm{~g} / \mathrm{cm}^{3}$ were obtained. The density values achieved were substantially higher than those obtained using conventional magnetron sputtering methods. The successful implementation of the strategy for increasing the ionization of $\mathrm{C}$ has been successfully demonstrated in this work. This work is thus a first step towards solving the major problem of low degree of $\mathrm{C}$ ionization in magnetron sputtering and it therefore opens-up new possibilities for magnetron sputtering based growth of carbon.

\section{Paper II}

Besides low degree of ionization, another issue that is of particular relevance to the synthesis of a-C thin films using magnetron sputtering is low growth rate which is a consequence of low sputtering yield of C. In this paper, we compiled a strategy to address the issue of low growth rates of carbon. The strategy was based on coupling a hydrocarbon gas (acetylene) with high density discharges. The discharges were generated using a superposition of HiPIMS and DCMS which allowed for varying the discharge density by tuning the HiPIMS/DCMS power fraction. We tuned discharge density, gas phase composition and energy of the ionized depositing species and achieved conditions capable of providing ten-fold increase in the deposition rate of a-C film growth compared to the growth rates obtained using Ar-HiPIMS discharge, paper I. This was achieved without severely compromising density, hardness and $\mathrm{H}$ content of the resulting films. The achieved mass densities $\left(\sim 2.32 \mathrm{~g} / \mathrm{cm}^{3}\right)$, low $\mathrm{H}$ content $(<10 \%)$ and high hardness (>25 GPa) entail improved film properties as compared to those obtained using RFPECVD and ICP-PECVD methods. This work addresses another challenging issue of low growth rates of carbon by providing a route for synthesizing dense and hard carbon films at significantly higher deposition rates. This makes this process viable for industrial scale deposition of amorphous carbon.

\section{Paper III}

In this paper we built upon knowledge gained in our previous studies by exploring the feasibility of adding high ionization potential buffer gas such as $\mathrm{Ne}$ to increase electron 
temperature in an $\mathrm{Ar} / \mathrm{C}_{2} \mathrm{H}_{2}$ HiPIMS discharge. We synthesized a-C thin films using a Ne$\mathrm{Ar} / \mathrm{C}_{2} \mathrm{H}_{2}$ based HiPIMS discharge process and investigated the discharge characteristics by studying the discharge current behavior. The discharge properties showed that a substantial amount of hydrocarbon ions were generated which gave rise to an increased discharge current as compared to Ne-Ar discharge with no acetylene. The ion generation was found to be affected by operating pressures and Ne fraction in the gas composition. We investigated the relevance of discharge characteristics with film properties. The mass densities of the films in the order of $2.2 \mathrm{~g} / \mathrm{cm}^{3}$ and hardness of the films up to $\sim 25 \mathrm{GPa}$ were obtained while $\mathrm{H}$ content of all of the films was below $15 \%$. The lowest $\mathrm{H}$ content was found to be $\sim 11 \%$. The most exciting outcome of the investigations on the films properties was low stress levels which were found not to exceed $100 \mathrm{MPa}$. Comparing these film properties with those in paper II, it can be concluded that admixing $\mathrm{Ne}$ in an Ar- $\mathrm{C}_{2} \mathrm{H}_{2}$ discharge, promotes dissociation of the $\mathrm{C}_{2} \mathrm{H}_{2}$. An advantage of an increased dissociation is the higher amount of $\mathrm{C}$ deposition while the downside of this is the possibility of incorporation higher amount of $\mathrm{H}$ into the films. Lower mass densities and higher $\mathrm{H}$ contents of the films grown using $\mathrm{Ne}-\mathrm{Ar} / \mathrm{C}_{2} \mathrm{H}_{2}$ discharge as compared to $\mathrm{Ar} / \mathrm{C}_{2} \mathrm{H}_{2}$ demonstrates this fact.

\section{Paper IV}

Papers IV and V and VI concern the second part of the thesis where the results from the investigations related to reactive HiPIMS processes of metal-oxides are reported. In this paper, differences in the discharge current behavior in non-reactive and reactive HiPIMS of metal-oxides, i.e. different shapes and peak current density, were studied. The aim of this work was to contribute towards understanding the physics of reactive HiPIMS processes by studying the discharge current behavior of $\mathrm{Ti}-\mathrm{O}$ and Al-O. The understanding was developed by investigating the ionic contributions as well as the time evolution of the sputtering and reactive gas ions $\left(\mathrm{Ar}^{1+}\right.$ and $\mathrm{O}^{1+}$ respectively) and sputtered metal ions $\left(\mathrm{Ti}^{1+}\right.$ and $\left.\mathrm{Al}^{1+}\right)$ to the discharge current. The effect of secondary electron emission yield of metal and oxide target surfaces along with the influence of the partial sputtering yields for $\mathrm{Ar}^{1+}, \mathrm{Ti}^{1+}, \mathrm{Al}^{1+}$ and $\mathrm{O}^{1+}$ on the discharge current were also investigated. It was found that in a reactive HiPIMS process, the discharge was dominated by ionized oxygen and the energy distribution functions of the $\mathrm{O}^{1+}$ ions 
resemble to that of the sputtered metal. It was established that the oxygen is preferentially sputtered from the target surface which means that the source of $\mathrm{O}^{1+}$ ions was the sputtering target rather than the gas phase. The ionized oxygen determines the discharge behavior in reactive HiPIMS, and its contribution to the observed increased discharge currents in oxide mode is vital. Another important finding of this paper is the observation that a strong gas depletion regime is never reached when operating in the oxide mode. The experimental observations of this research were also supported by TRIDYN simulations. In this work, we have contributed to the fundamental understanding of reactive HiPIMS discharge characteristics which is among the first such studies on the subject. This work therefore provides us a platform to further understand the physics of reactive HiPIMS discharges.

\section{Paper $V$}

The invesitgations on the discharge characteristics in paper IV were made only for elemental targets. In order to understand the discharge characteristics of reactive HiPIMS process based on alloy targets involving materials which exhibit lower sputtering yields, higher ionization cross-section as well as high SEEC when oxidized as compared to metals, we employed Al-Si alloy target and investigated the Al-Si and Al-Si-O discharge characteristics under varied target compositions $\left(\mathrm{Al}_{0.5} \mathrm{Si}_{0.5}\right.$ and $\left.\mathrm{Al}_{0.1} \mathrm{Si}_{0.9}\right)$. A comparision of the discharge behaviour of Al-Si-O with that of Al-O was also made. The choice of Al$\mathrm{Si}-\mathrm{O}$ system was based on its relevance to the desired investigations as well as its importance for the technological applications. Al-Si-O, owing to the possibility of combining attributes such as low refractive index and high hardness in a single layer, is a promising candidate for anti-reflective and solar thermal applications. Similar to Ti-O and $\mathrm{Al}-\mathrm{O}$ in paper IV, the investigations in this work were carried out by analysing the discharge current behaviour, by measuring the ionic contribution to the discharge current (ionized fluxes of $\mathrm{Ar}, \mathrm{O}, \mathrm{Al}$ and $\mathrm{Si}$ ) as well as by measuring the plasma parameters (electron density and electron temperature). Time evolution of the ionized fluxes was also studied during the pulse-on time as well as in the post-discharge in order to investigate its correlation with the time evolution of the discharge current. In order to gain an insight into the correlation between discharge characteristics and film growth, Al-Si-O films were also grown and its properties (chemical composition and optical properties) were 
investigated. The discharge current behaviour in the oxide mode of Al-Si-O discharges were found to be similar to that in Al-O discahrge. The observed differences in the discharge current characteristics between the metal and oxide modes in Al-O discharge, which are mainly attributed to the presence of large oxygen ion fluxes, were also found in Al-Si-O discharge. In the latter case, large fluxes of oxygen ions were also generated which were found to affect the discharge characteristics however, the influence of SEEC especially for low $\mathrm{Al} / \mathrm{Si}$ ratio also contributed substantially to the discharge current characteristics. The grown Al-Si-O thin films were found to be amorphous with their refractive indicies correlating well with the film stoichiometry. This work is the first study on exploring the potential of HiPIMS for synthesizing Al-Si-O based antireflective coatings. The knowledge gained in this study is important for developing the wearresistant, antireflective coatings. It also widens up the application area of HiPIMS processes.

\section{Paper VI}

In this paper, the influence of HiPIMS peak power on the phase formation and properties of $\mathrm{TiO}_{2}$ thin films were investigated in comparison to DCMS. Investigations on plasma chemistry and plasma energetics are also carried out and a correlation of plasma properties with the film properties was sought. It was found that the phase composition of $\mathrm{TiO}_{2}$ can be controlled by HiPIMS peak power and $\mathrm{TiO}_{2}$ thin films exhibiting pure rutile, pure anatase and mixture of both rutile and anatase can be synthesized by varying HiPIMS peak power. The investigations on the plasma properties showed that besides energetic $\mathrm{Ti}^{1+}$ ions, highly energetic $\mathrm{O}^{1+}$ ions are also present in the discharge. The energy distributions of these ions correlated well with the changes in the HiPIMS peak power and film properties. Superior film properties (refractive index and density) were obtained for the films synthesized using HiPIMS as compared to DCMS. 


\section{Chapter 7}

\section{Additional results and future outlook}

The results presented so far demonstrate that highly ionized $\mathrm{C}$ fluxes can be obtained by using Ne-based HiPIMS process, which facilitates the growth of high density a-C films. The further optimization of the process and future research will continue in the similar fashion i.e. new ways will be developed to enhance the plasma properties and the influence on the film properties will be investigated.

Relevant to the studies on paper I, where the proof of the concept was presented in the form of plasma and film properties., a detailed investigation on the plasma chemistry and plasma dynamics has been performed which included the plasma diagnostics on Ar- $\mathrm{Ne}$ as well as Kr-based HiPIMS discharges. The purpose of the study was to further elaborate and explore the HiPIMS discharge characteristics under different sputtering gas phase composition. The main finding of the study is that an increased $\mathrm{C}^{+}$ion flux is obtained with an increased ionization potential of the buffer gas. This means that Kr-based process, due to low ionization potential of $\mathrm{Kr}$, entails lower $\mathrm{C}^{+}$fluxes and vice versa. Furthermore, in Ne-based HiPIMS discharge large amounts of doubly ionized $\mathrm{C}$ are also measured which is a consequence of higher electron temperatures in the discharge. A detailed investigation on the film properties was also initiated where initially the hardness of a-C thin films grown using Ar- and Ne-based processes were obtained. The films grown using Ne-based HiPIMS process at 4.66 Pa exhibited a significantly high hardness which, for the substrate bias potential of $100 \mathrm{~V}$, entails a hardness value of about $50 \mathrm{GPa}$. However, since the films exhibit poor adhesion when thickness exceeds about $300 \mathrm{~nm}$, therefore the adhesion improvement studies are desired.

For the metal-oxide based HiPIMS processes, the properties of Al-Si-O thin films are further needed to be explored. So far, the films grown at room temperature did not exhibit 
the desired hardness (i.e. > $20 \mathrm{GPa}$ ) while the refractive index lower than 1.6 are obtained for the room temperature grown films. Therefore, the film synthesis at elevated growth temperature is the next step towards achieving the goal of antireflective, wear resistant Al-Si-O thin films.

The a-C films containing high $s p^{3}$ bond fraction are known to suffer with residual stresses as well as with poor adhesion of the films to the substrate. The aim of one of the future study is to address these issues. The goal is to demonstrate the good adhesion of thicker (in the order of micron) and $s p^{3}$ rich a-C films on steel substrates.

The feasibility of sideways deposition of thin films using the dual-magnetron open-field approach has so far been demonstrated by using Ti. In the future study, the sideways deposition of a-C films will be performed by employing the newly developed Ne-based HiPIMS process. The conventional Ar-HiPIMS process will also be used to investigate the effect of the degree of ionization of the sputtered $\mathrm{C}$ on the sideways transport as well as on the microstructure of the depositing films. 


\section{References}

[1] M. Ohring, Materials Science of Thin Films: Depositions \& Structure, 2nd ed., Academic Press, San Diego, USA, (2002).

[2] P.M. Martin (Ed.), Handbook of Deposition Technologies for Films and Coatings, 3rd ed., Elsevier Inc., Oxford, (2010).

[3] S.K. Sree Harsha, Principles of Physical Vapor Deposition of Thin Films, Elsevier Ltd, Oxford, (2006).

[4] M.J. Hampden-Smith, T.T. Kodas, Chemical Vapor Deposition of Metals : Part 1. An Overview of CVD Processes, Chem. Vap. Depos. 1 (1995) 8-23.

[5] A. Anders, Energetic deposition using filtered cathodic arc plasmas, Vacuum. 67 (2002) 673-686.

[6] A. Anders, Fundamentals of pulsed plasmas for materials processing, Surf. Coatings Technol. 183 (2004) 301-311.

[7] S.M. Rossnagel, Magnetron plasma deposition processes, Thin Solid Films. 171 (1989) $125-142$.

[8] U. Helmersson, M. Lattemann, J. Bohlmark, A.P. Ehiasarian, J. Gudmundsson, Ionized physical vapor deposition (IPVD): A review of technology and applications, Thin Solid Films. 513 (2006) 1-24.

[9] J.T. Gudmundsson, N. Brenning, D. Lundin, U. Helmersson, High power impulse magnetron sputtering discharge, (2012).

[10] K. Sarakinos, J. Alami, S. Konstantinidis, High power pulsed magnetron sputtering: A review on scientific and engineering state of the art, Surf. Coatings Technol. 204 (2010) $1661-1684$.

[11] J. Alami, P. Eklund, J. Andersson, M. Lattemann, E. Wallin, J. Bohlmark, et al., Phase tailoring of Ta thin films by highly ionized pulsed magnetron sputtering, Thin Solid Films. 515 (2007) 3434-3438.

[12] J. Alami, P.O.Å. Persson, D. Music, J.T. Gudmundsson, J. Bohlmark, U. Helmersson, Ionassisted physical vapor deposition for enhanced film properties on nonflat surfaces, J. Vac. Sci. Technol. A 23 (2005) 278.

[13] J. Robertson, Diamond-like amorphous carbon, Mater. Sci. Eng. R. 37 (2002) 129-281.

[14] S. Logothetidis, M. Gioti, P. Patsalas, C. Charitidis, Insights on the deposition mechanism of sputtered amorphous carbon films, Carbon N. Y. 37 (1999) 765-769. 


\section{Appended Papers}

The articles associated with this thesis have been removed for copyright reasons. For more details about these see:

http://urn.kb.se/resolve?urn=urn:nbn:se:liu:diva-104265 
[15] K. Sarakinos, A. Braun, C. Zilkens, S. Mráz, J.M. Schneider, H. Zoubos, et al., Exploring the potential of high power impulse magnetron sputtering for growth of diamond-like carbon films, Surf. Coatings Technol. 206 (2012) 2706-2710.

[16] B.M. Dekoven, P.R. Ward, R.E. Weiss, S. Clara, D.J. Christie, R.A. Scholl, et al., Carbon Thin Film Deposition Using High Power Pulsed Magnetron Sputtering, 46th Annu. Tech. Conf. Proc. (2003) 158-165.

[17] C.W. Kimblin, Erosion and ionization in the cathode spot regions of vacuum arcs, J. Appl. Phys. 44 (1973) 3074.

[18] D.M. Sanders, A. Anders, Review of cathodic arc deposition technology at the start of the new millennium, Surf. Coatings Technol. 133-134 (2000) 78-90.

[19] S. Xu, B.K. Tay, H.S. Tan, L. Zhong, Y.Q. Tu, S.R.P. Silva, et al., Properties of carbon ion deposited tetrahedral amorphous carbon films as a function of ion energy, J. Appl. Phys. 79 (1996) 7234.

[20] D. Lundin, K. Sarakinos, An introduction to thin film processing using high-power impulse magnetron sputtering, J. Mater. Res. 27 (2012) 780-792.

[21] E. Wallin, T.I. Selinder, M. Elfwing, U. Helmersson, Synthesis of $\alpha$-Al 2 O 3 thin films using reactive high-power impulse magnetron sputtering, EPL (Europhysics Lett. 82 (2008) 36002.

[22] V. Straňák, M. Quaas, H. Wulff, Z. Hubička, S. Wrehde, M. Tichý, et al., Formation of TiO x films produced by high-power pulsed magnetron sputtering, J. Phys. D. Appl. Phys. 41 (2008) 055202.

[23] K. Sarakinos, J. Alami, C. Klever, M. Wuttig, Process stabilization and enhancement of deposition rate during reactive high power pulsed magnetron sputtering of zirconium oxide, Surf. Coatings Technol. 202 (2008) 5033-5035.

[24] M.A. Lieberman, Principles of Plasma Discharges and Materials Processing, 2nd ed., John Willey \& Sons, Inc., Hoboken, New Jersey, (2005).

[25] A. Anders (Ed.), Handbook of Plasma Immersion Ion Implantation and Deposition, Wiley-VCH Verlag GmbH \& Co. KGaA, Weinheim, (2004).

[26] Table of atomic data: http://www.nist.gov/, accessed December 2013.

[27] J.A. Hopwood, Thin Films: Ionized Physical Vapor Deposition, Academic Press, San Diego, USA, (2000).

[28] J. Hopwood, F. Qian, Mechanisms for highly ionized magnetron sputtering, J. Appl. Phys. 78 (1995) 758. 
[29] F. Magnus, O.B. Sveinsson, S. Olafsson, J.T. Gudmundsson, Current-voltage-time characteristics of the reactive $\mathrm{Ar} / \mathrm{N}_{2}$ high power impulse magnetron sputtering discharge, J. Appl. Phys. 110 (2011) 083306.

[30] Table of molecules: http://www.nist.gov/, accessed December 2013.

[31] K. De Bleecker, A. Bogaerts, W. Goedheer, Detailed modeling of hydrocarbon nanoparticle nucleation in acetylene discharges, Phys. Rev. E. 73 (2006) 026405.

[32] R.S. Freund, C. Robert, R.J. Shul, T.R. Hayes, T. Laboratories, M. Hill, Cross-section measurements for electron-impact ionization of atoms, Phys. Rev. 41 (1990) 3575-3595.

[33] R. Behrisch (Ed.), Sputtering by particle bombardment I, Springer (1982).

[34] D. Depla, Magnetron, reactive gases and sputtering, 1st ed., (2013).

[35] R.A. Baragiola, E.V. Alonso, J. Ferron, A. Oliva-Florio, Ion-induced electron emission from clean metals, Surf. Sci. 90 (1979) 240-255.

[36] A.V. Phelps, Z.L. Petrovic, Cold-cathode discharges and breakdown in argon : surface and gas phase production of secondary electrons, Plasma Sources Sci. Technol. 8 (1999) R21R44.

[37] D. Depla, S. Heirwegh, S. Mahieu, J. Haemers, R. De Gryse, Understanding the discharge voltage behavior during reactive sputtering of oxides, J. Appl. Phys. 101 (2007) 013301.

[38] S.M. Rossnagel, Current-voltage relations in magnetrons, J. Vac. Sci. Technol. A Vacuum, Surfaces, Film. 6 (1988) 223.

[39] S.M. Rossnagel, Metal ion deposition from ionized mangetron sputtering discharge, J. Vac. Sci. Technol. B Microelectron. Nanom. Struct. 12 (1994) 449.

[40] J. Bohlmark, J. Alami, C. Christou, A.P. Ehiasarian, U. Helmersson, Ionization of sputtered metals in high power pulsed magnetron sputtering, J. Vac. Sci. Technol. A Vacuum, Surfaces, Film. 23 (2005) 18.

[41] J. Bohlmark, M. Lattemann, J.T. Gudmundsson, a. P. Ehiasarian, Y. Aranda Gonzalvo, N. Brenning, et al., The ion energy distributions and ion flux composition from a high power impulse magnetron sputtering discharge, Thin Solid Films. 515 (2006) 1522-1526.

[42] K. Bobzin, N. Bagcivan, P. Immich, S. Bolz, J. Alami, R. Cremer, Advantages of nanocomposite coatings deposited by high power pulse magnetron sputtering technology, J. Mater. Process. Technol. 209 (2009) 165-170.

[43] A. Aijaz, D. Lundin, P. Larsson, U. Helmersson, Dual-magnetron open field sputtering system for sideways deposition of thin films, Surf. Coatings Technol. 204 (2010) 21652169. 
[44] D. Lundin, N. Brenning, D. Jädernäs, P. Larsson, E. Wallin, M. Lattemann, et al., Transition between the discharge regimes of high power impulse magnetron sputtering and conventional direct current magnetron sputtering, Plasma Sources Sci. Technol. 18 (2009) 045008.

[45] F. Magnus, J.T. Gudmundsson, Digital smoothing of the Langmuir probe I-V characteristic., Rev. Sci. Instrum. 79 (2008) 073503.

[46] A. Anders, J. Andersson, A. Ehiasarian, High power impulse magnetron sputtering: Current-voltage-time characteristics indicate the onset of sustained self-sputtering, J. Appl. Phys. 102 (2007) 113303.

[47] A. Anders, Discharge physics of high power impulse magnetron sputtering, Surf. Coatings Technol. 205 (2011) S1-S9.

[48] J.M. Andersson, Z. Czigány, P. Jin, U. Helmersson, Microstructure of $\alpha$-alumina thin films deposited at low temperatures on chromia template layers, J. Vac. Sci. Technol. A Vacuum, Surfaces, Film. 22 (2004) 117.

[49] S. Berg, T. Nyberg, Fundamental understanding and modeling of reactive sputtering processes, Thin Solid Films. 476 (2005) 215-230.

[50] W.D. Sproul, High-rate reactive DC magnetron sputtering of oxide and nitride superlattice coatings, Vacuum. 51 (1998) 641-646.

[51] D. Depla, R. De Gryse, Target poisoning during reactive magnetron sputtering: Part I: the influence of ion implantation, 281 (2003).

[52] M. Audronis, V. Bellido-Gonzalez, Investigation of reactive high power impulse magnetron sputtering processes using various target material-reactive gas combinations, Surf. Coatings Technol. 205 (2011) 3613-3620.

[53] D. Depla, R. De Gryse, Cross section for removing chemisorbed oxygen from an aluminum target by sputtering, J. Vac. Sci. Technol. A. 20 (2002) 521.

[54] G. Greczynski, L. Hultman, Time and energy resolved ion mass spectroscopy studies of the ion flux during high power pulsed magnetron sputtering of $\mathrm{Cr}$ in $\mathrm{Ar}$ and $\mathrm{Ar} / \mathrm{N}_{2}$ atmospheres, Vacuum. 84 (2010) 1159-1170.

[55] T. Michely, J. Krug, Islands, Mounds and Atoms, Patterns and Processes in Crystal Growth Far from Equilibrium, Springer-Verlag, Berlin (2004).

[56] M. Raible, S.G. Mayr, S.J. Linz, M. Moske, Amorphous thin-film growth: Theory compared with experiment, Eur. Lett. 50 (2000) 61-67.

[57] G.S. Bales, R. Bruinsma, E.A. Eklund, R.P.U. Karunasiri, A. Zangwill, A. Eklund, et al., Growth and Erosion of Thin Solid Films, Science (80-. ). 249 (1990) 264-268. 
[58] C.A. Charitidis, Nanomechanical and nanotribological properties of carbon-based thin films: A review, Int. J. Refract. Met. Hard Mater. 28 (2010) 51-70.

[59] J. Robertson, Deposition mechanism of a-C and a-C:H, J. Non. Cryst. Solids. 164-166 (1993) 1115-1118.

[60] T. Frauenheim, P. Blaudeck, U. Stephan, G. Jungnickel, Atomic structure and physical properties of amorphous carbon and its hydrogenated analogs., Phys. Rev. B. Condens. Matter. 48 (1993) 4823-4834.

[61] J. Robertson, Mechanism of $\mathrm{sp}^{3}$ bond formation in the growth of diamond-like carbon, Diam. Relat. Mater. 14 (2005) 942-948.

[62] P.J. Fallon, V.S. Veerasamy, C.A. Davis, J. Robertson, G.A. Amaratung, W.I. Milne, Properties of filtered-ion-beam-deposited diamondlike carbon as a function of ion energy, Phys. Rev. B. 48 (1993) 4777-4782.

[63] A.C. Ferrari, A. Libassi, B. Tanner, V. Stolojan, J. Yuan, L. Brown, et al., Density, sp ${ }^{3}$ fraction, and cross-sectional structure of amorphous carbon films determined by x-ray reflectivity and electron energy-loss spectroscopy, Phys. Rev. B. 62 (2000) 11089-11103.

[64] P.J. Martin, A. Bendavid, T.J. Kinder, Control of film properties during filtered arc deposition, Surf. Coatings Technol. 81 (1996) 36-41.

[65] R. Lossy, D.L. Pappas, R. A. Roy, J.J. Cuomo, V.M. Sura, Filtered arc deposition of amorphous diamond, Appl. Phys. Lett. 61 (1992) 171.

[66] P. Tsai, K. Chen, Evaluation of microstructures and mechanical properties of diamond like carbon films deposited by filtered cathodic arc plasma, Thin Solid Films. 516 (2008) $5440-5444$.

[67] R. Lossy, D.L. Pappas, R. A. Roy, J.P. Doyle, J.J. Cuomo, J. Bruley, Properties of amorphous diamond films prepared by a filtered cathodic arc, J. Appl. Phys. 77 (1995) 4750 .

[68] A.A. Voevodin, M.S. Donley, Preparation of amorphous diamond-like carbon by pulsed laser deposition : a critical review, Surf. Coatings Technol. 82 (1996) 199-213.

[69] R. Eason, Pulsed Laser Deposition of Thin Films: Applications-led Growth of Functional Materials, Wiley (2006).

[70] L. Miao, P. Jin, K. Kaneko, A. Terai, N. Nabatova-Gabain, S. Tanemura, Preparation and characterization of polycrystalline anatase and rutile $\mathrm{TiO}_{2}$ thin films by of magnetron sputtering, Appl. Surf. Sci. 212-213 (2003) 255-263.

[71] K. Sunada, Bactericidal and Detoxification Effects of $\mathrm{TiO}_{2}$ Thin Film Photocatalysts, 32 (1998) 726-728. 
[72] A. Fujishima, T.N. Rao, D.A. Tryk, TiO2 photocatalysts and diamond electrodes, Electrochem. Acta. 45 (2000) 4683-4690.

[73] T. Lindgren, J.M. Mwabora, E. Avendan, J. Jonsson, A. Hoel, C.-G. Granqvist, et al., Photoelectrochemical and Optical Properties of Nitrogen Doped Titanium Dioxide Films Prepared by Reactive DC Magnetron Sputtering, J. Phys. Chem. B. 107 (2003) 57095716.

[74] M.D. Wiggins, Phase development in sputter deposited titanium dioxide, J. Vac. Sci. Technol. A Vacuum, Surfaces, Film. 14 (1996) 772.

[75] D. Wicaksana, Process effects on structural properties of $\mathrm{TiO}_{2}$ thin films by reactive sputtering, J. Vac. Sci. Technol. A. 10 (1992) 1479.

[76] M. Åstrand, T.I. Selinder, F. Fietzke, H. Klostermann, PVD- $\mathrm{Al}_{2} \mathrm{O}_{3}$-coated cemented carbide cutting tools, Surf. Coatings Technol. 188-189 (2004) 186-192.

[77] K. Koski, J. Hölsä, P. Juliet, Properties of aluminium oxide thin films deposited by reactive magnetron sputtering, Thin Solid Films. 339 (1999) 240-248.

[78] O. Zywitzki, G. Hoetzsch, F. Fietzke, K. Goedicke, Effect of the substrate temperature on the structure and properties of $\mathrm{Al}_{2} \mathrm{O}_{3}$ layers reactively deposited by pulsed magnetron sputtering, Surf. Coatings Technol. 82 (1996) 169-175.

[79] O. Kyrylov, D. Kurapov, J.M. Schneider, Effect of ion irradiation during deposition on the structure of alumina thin films grown by plasma assisted chemical vapour deposition, Appl. Phys. A. 80 (2004) 1657-1660.

[80] D. Kurapov, J. Reiss, D.H. Trinh, L. Hultman, J.M. Schneider, Influence of the normalized ion flux on the constitution of alumina films deposited by plasma-assisted chemical vapor deposition, J. Vac. Sci. Technol. A 25 (2007) 831.

[81] M.M. Makhlouf, H. V Guthy, The aluminum - silicon eutectic reaction : mechanisms and crystallography, J. Light Met. 1 (2001) 199-218.

[82] F.J. Klug, S. Prochazka, R.H. Doremus, Alumina-Silica Phase Diagram in the Mullite Region, J. Am. Chem. Soc. 70 (1987) 750-759.

[83] V.A. Izhevskiy, L.A. Genova, J.C. Bressiani, F. Aldinger, Progress in SiAlON ceramics, J. Eur. Ceram. Soc. 20 (2000) 2275-2295.

[84] I.A. Aksay, D.M. Dabbs, M. Sarikaya, Mullite for Structural, Electronic, and Optical Applications, J. Am. Chem. Soc. 74 (1991) 2343-2358.

[85] M. Verdenelli, S. Parola, F. Chassagneus, J.. Letoffe, H. Vincent, J.-P. Scharff, et al., Solgel preparation and thermo-mechanical properties of porous $\mathrm{xAl}_{2} \mathrm{O}_{3}-\mathrm{ySiO}{ }_{2}$ coatings on $\mathrm{SiC}$ Hi-Nicalon fibres, J. Eur. Ceram. Soc. 23 (2003). 
[86] U. Schallenberg, Design principle for broadband AR coatings, in: N. Kaiser, M. Lequime, H.A. Macleod (Eds.), Adv. Opt. Thin Film. III Proc. SPIE Vol. 7101 (2008) pp. 103-1.

[87] U. Schallenberg, U. Schulz, N. Kaiser, Multicycle AR coatings: a theoretical approach, in: Adv. Opt. Thin Film. Proc. SPIE Vol. 5205 (2004) pp. 357-366.

[88] D.R. Cairns, A.J. Kessman, P.J. Richter, F.J. Bottari, N.X. Randall, Mechanical and tribological investigations of sol-gel derived SiO2 optical coatings, Wear. 265 (2008) 411-416.

[89] V.A. Godyak, R.B. Piejak, B.M. Alexandrovich, Probe diagnostics of non-Maxwellian plasmas, J. Appl. Phys. 73 (1993) 3657-3663.

[90] J.T. Gudmundsson, J. Alami, U. Helmersson, Spatial and temporal behavior of the plasma parameters in a pulsed magnetron discharge, Surf. Coatings Technol. 161 (2002) 249-256.

[91] J. Bohlmark, Doctoral Thesis: Fundamentals of High Power Impulse Magnetron Sputtering, Linköping University, (2005).

[92] P.E. Miller, M.B. Denton, The quadrupole mass filter: Basic operating concepts, J. Chem. Educ. 63 (1986) 617.

[93] M. Birkholz, Thin Film Analysis by X-Ray Scattering, Wiley-VCH Verlag GmbH \& Co. KGaA, Weinheim, FRG, (2005).

[94] A. LiBassi, A.C. Ferrari, V. Stolojan, B.. Tanner, J. Robertson, L. Brown, Density, sp ${ }^{3}$ content and internal layering of DLC films by X-ray reflectivity and electron energy loss spectroscopy, Diam. Relat. Mater. 9 (2000) 771-776.

[95] H.J. Whitlow, G. Possnert, C.. Petersson, No Ti, Nucl. Instruments Methods Phys. Res. Sect. B Beam Interact. with Mater. Atoms. 27 (1987) 448.

[96] J. Jensen, D. Martin, A. Surpi, T. Kubart, ERD analysis and modification of $\mathrm{TiO}_{2}$ thin films with heavy ions, Nucl. Instruments Methods Phys. Res. Sect. B Beam Interact. with Mater. Atoms. 268 (2010) 1893-1898.

[97] A.C. Ferrari, J. Robertson, Resonant Raman spectroscopy of disordered, amorphous, and diamondlike carbon, Phys. Rev. B. 64 (2001) 075414.

[98] A.C. Ferrari, J. Robertson, Interpretation of Raman spectra of disordered and amorphous carbon, Phys. Rev. B. 61 (2000) 14095-14107.

[99] C. Casiraghi, A.C. Ferrari, J. Robertson, Raman spectroscopy of hydrogenated amorphous carbons, Phys. Rev. B. 72 (2005) 1-14.

[100] G.G. Stoney, The Tension of Metallic Films Deposited by Electrolysis, in: Proc. R. Soc. London. Ser. A 82, (1909) pp. 172-175. 
[101] G.C.A.M. Janssen, M.M. Abdalla, F. van Keulen, B.R. Pujada, B. van Venrooy, Celebrating the 100th anniversary of the Stoney equation for film stress: Developments from polycrystalline steel strips to single crystal silicon wafers, Thin Solid Films. 517 (2009) 1858-1867.

[102] W.C. Oliver, G.M. Pharr, An improved technique for determining hardness and elastic modulus using load and displacement sensing indentation experiments, J. Mater. Res. 7 (1992) 1564-1583. 


\section{Appended Papers}

The articles associated with this thesis have been removed for copyright reasons. For more details about these see:

http://urn.kb.se/resolve?urn=urn:nbn:se:liu:diva-104265 